THYROID

Volume X, Number X, 201X

(c) Mary Ann Liebert, Inc.

DOI: 10.1089/thy.2016.0373

\title{
In vivo Functional Consequences of Human THRA Variants Expressed in the Zebrafish
}

\author{
Federica Marelli, ${ }^{1}$ Silvia Carra, ${ }^{2}$ Giuditta Rurale, ${ }^{3}$ Franco Cotelli, and Luca Persani ${ }^{1,4_{L}}$
}

Heterozygous mutations in the thyroid hormone receptor alpha (THRA) gene cause resistance to thyroid hormone alpha $(\mathrm{RTH} \alpha)$, a disease characterized by variable manifestations reminiscent of untreated congenital hypothyroidism but a raised triiodothyronine/thyroxine ratio and normal thyrotropin levels. It was recently described that zebrafish embryos expressing a dominant negative (DN) form of thraa recapitulate the key features of $\mathrm{RTH} \alpha$, and that zebrafish and human receptors are functionally interchangeable. This study expressed several human thyroid hormone receptor alpha (hTR $\alpha$ ) variants in zebrafish embryos and analyzed the resulting phenotypes. All hTR $\alpha$-injected embryos showed variable defects, including cerebral and cardiac edema likely caused by an aberrant looping during heart development, anemia, and an incomplete formation of the vascular network. Moreover, the hTR $\alpha$-injected embryos presented severe defects of motorneurons and craniofacial development, thus affecting their autonomous feeding and swimming behaviors. Surprisingly, expression of all hTR $\alpha$ mutants had no detectable effect on thyrotropin beta and thyrotropin-releasing hormone transcripts, indicating that their DN action is limited on the thyroid hormone reception beta 2 targets at the hypothalamic/pituitary level in vivo. As previously described in vitro, treatment with high triiodothyronine doses can efficiently revert the observed defects only in embryos injected with missense hTR $\alpha$ variants. In conclusion, injection of human THRA variants in zebrafish embryos causes tissue-specific defects recapitulating most of the RTH $\alpha$ clinical and biochemical manifestations. The described manipulation of zebrafish embryos represents a novel in vivo model to screen the functional consequences of THRA variants and the rescue potential of new therapeutic compounds.

Keywords: zebrafish, THRA, heart development, embryonic development, resistance to thyroid hormone, thyroid

\section{Introduction}

$\mathbf{T}$ HE CLINICAL PRESENTATION OF resistance to thyroid hormone alpha $(\mathrm{RTH} \alpha)$ includes a variable combination of dysmorphic features. There are signs of untreated congenital hypothyroidism $(\mathrm{CH})$, including growth retardation (associated with delayed bone development and skeletal dysplasia), macrocephaly, chronic constipation, mental retardation, psychomotor defects, bradycardia, anemia, and low metabolic rate. Unlike $\mathrm{CH}$ patients, the biochemical signature of RTH $\alpha$ is a high triiodothyronine (T3)/thyroxine (T4) ratio and a low T4 associated with normal thyrotropin (TSH) and thyroid volume (1-10). It has been suggested that such changes in thyroid hormone (TH) levels may reflect tissue hypothyroidism and consequent modifications in $\mathrm{TH}$ metabolism (6). The impact of treatment of $\mathrm{RTH} \alpha$ patients with levothyroxine (LT4) has so far been uncertain due to several factors, including delayed initiation of therapy and use of variable doses. At physiologic doses, there is usually a rapid suppression of TSH. Conversely, bradycardia, energy level, and bowel function are less affected, reflecting the TH resistance in organs such as myocardium, skeletal muscle, and gastrointestinal tract that predominantly express thyroid hormone receptor alpha 1 (TR $\alpha 1)$, with preservation of TH sensitivity in thyroid hormone receptor beta $(\operatorname{TR} \beta)$ expressing tissues (e.g., the hypothalamic-pituitary-thryroid [HPT] axis). On the other hand, high LT4 doses ameliorate the clinical conditions in certain RTH $\alpha$ cases but with several adverse thyrotoxic effects (11).

The molecular basis of $\mathrm{RTH} \alpha$ has been investigated in animal models. The phenotypic alterations described in mouse models with artificially introduced TR $\alpha 1$ mutations

\footnotetext{
AU2 ${ }^{1}$ Laboratorio Sperimentale di Ricerche Endocrino-Metaboliche, Istituto Auxologico Italiano, Milan, Italy.

${ }^{2}$ Dipartimento di Bioscienze; ${ }^{3}$ Dipartimento-di Biotecnologie Mediche e Medicina Translazionale; ${ }^{4}$ Dipartiment ${ }^{2}$ ur Scienze Cliniche e di Comunità; Università degli Studi di Milano, Milan, Italy.
} 
are usually consistent with those reported in human cases. However, high TSH levels have been found in several murine models, in contrast to the findings reported in human patients with RTH $\alpha(12-20)$.

The protein structure of the TRs is highly conserved across vertebrates, particularly in the DNA-binding (DBD) and ligand-binding (LBD) domains, reaching $90-95 \%$ of identity between human and zebrafish receptors. Therefore, in a previous study (21), embryos harboring endogenous DN mutations in the LBD of zebrafish TR $\alpha$ isoforms were generated by morpholino microinjection. Those morphant embryos recapitulated most of the key clinical and biochemical manifestations (e.g., growth and brain defects, delayed cartilage development, defective heart function, high T3/T4 ratio) described in $\mathrm{RTH} \alpha$ patients. In these thraa morphants, increased pituitary dio 2 and reduced dio $3 a$ and dio $3 b$ expression was observed, which explains the peculiar biochemical features found in RTH $\alpha$. It was also reported that zebrafish and human TRs were functionally interchangeable, and that high $\mathrm{T} 3$ doses partially reverted the DN action of mutant hTR $\alpha$ in thraa morphants.

The present work developed a simplified model and evaluated the molecular and functional tissue consequences of several human THRA mutations (i.e., D211G (10), A263V (5), A382PfsX7 (3), E403X (1), and F397fs406X (2)) by directly forcing their expression in zebrafish embryos. The injected embryos were then subjected to a series of experiments in order to analyze the effects of hTR $\alpha$ mutations during zebrafish development, particularly focusing on tissues and functions that are affected in patients with $\mathrm{RTH} \alpha$. Finally, the ability of T3 treatment to rescue the disease phenotype of embryos injected with the different THRA variants was tested.

\section{Materials and Methods}

The amino acid alignment of the different zebrafish TR (zTR) isoforms and the human TR $\alpha 1$ (hTR $\alpha 1)$ and hTR $\alpha 2$ proteins (including the localization of the THRA variants

SF1 studied in this work) is reported in Supplementary Figure S1 (Supplementary Data are available online at www.liebertpub .com/thy).

\section{Fish line and maintenance}

Zebrafish (Danio rerio) from wild-type (AB) and $\operatorname{tg}(g a-$ tal:dsRed)sd2; $\operatorname{tg}(k d r l:$ EGFP)S843 (22) adults were maintained in controlled conditions, and all procedures were performed in accordance with Italian and European regulations (D. Lgs no. 2014/26, implementation of the 2010/63/ UE). As no experiments were foreseen beyond five days post fertilization (dpf), the Institutional Review Board approved the protocol. Zebrafish embryos, obtained from natural spawning, were raised and maintained according to established techniques (23) and staged according to morphological criteria (24). For whole mount in situ hybridization (WISH) and immunohistochemistry (IHC) experiments, from 24 hours post fertilization (hpf), the embryos were cultured in fish water containing $0.002 \%$ of 1-phenyl-2-thiourea (Sigma) that prevents embryonic pigmentation without side effects on TH synthesis (21).
mRNA synthesis, microinjection, and treatment of zebrafish embryos

The human THRA (ENST00000450525) mutant plasmids were linearized and in vitro transcribed using the mMESSAGE mMACHINET7 kit (Ambion), followed by RNA purification using the Megaclear kit (Ambion), according to the manufacturer's protocols. Each hTR $\alpha$ transcript was injected in zebrafish eggs at the one- to two-cell stage at a dose of $80 \mathrm{pg} / \mathrm{embryo}$. Starting from $6 \mathrm{hpf}$, the injected embryos were treated with $20 \mu \mathrm{M}$ of dimethyl-sulfoxide (DMSO; Sigma) or $20 \mu \mathrm{M}$ of T3 (IBSA-Farmaceutici). Uninjected embryos treated with the same dose of DMSO were used as controls.

\section{WISH and IHC}

To study the cardiac and thyroid function, WISH was performed (25) using the following probes: cmlc2 (26), $t g$ (27), tshba (28), dio2 (29), dio3a, and dio3b (30). The DIGprobes were detected using anti-DIG-alkaline phosphatase (AP) and NBT/BCIP or FastBlue staining, as previously described (27). For IHC, embryos were exposed to antimouse primary antibodies (1:200 of znp1, a4-1025, or zn5; ZIRC) (31) or rabbit anti-T4 (1:1000; ICN Biochemicals), and 1:200 of AlexaFluor 488 anti-mouse or anti-rabbit IgG (Invitrogen) as secondary antibody. After WISH and IHC, embryos were post-fixed in $4 \%$ paraformaldehyde (PFA), washed three times in phosphate-buffered saline (PBS) $+0.1 \%$ Tween 20 , rinsed in $85 \%$ glycerol/PBS, and then submitted to image acquisition.

\section{RNA isolation and quantitative real-time polymerase chain reaction}

Total RNA from pools of 50 embryos at different stages was extracted with Trizol Reagent (Invitrogen) and then reversed transcribed using the ImProm-II Reverse Transcription System (Promega) according to the manufacturers' instructions. Quantitative real-time polymerase chain reaction (qRT-PCR) was analyzed on an ABI7300 System (PerkinElmer Applied Biosystems) and SYBRGreen MasterMix (Invitrogen). The relative mRNA expression was measured and normalized against the housekeeping gene eef $1 \alpha$ using the $2^{-\Delta \Delta \mathrm{Ct}}$ method. Values represent the mean \pm standard deviation $(S D)$ of three experiments, performed independently. The list of primers is available upon request.

\section{Heart-rate counts of zebrafish embryos}

Heart rates (beats per minute) were counted manually under the Leica MZFLIII stereomicroscope in injected embryos and uninjected controls at $2 \mathrm{dpf}$. Embryos were first anesthetized by adding $0.016 \%$ Tricaine (ethyl3-aminobenzoate methanesulfonate salt; Sigma), which did not have any effect on the zebrafish heart rate (32). Results are expressed as the mean $\pm S D$ of three experiments (15 embryos in each experiment)

\section{Analysis of vascular development}

To study the architecture of zebrafish vasculature and the circulating blood cells, $\operatorname{tg}($ gatal:dsRed $) \operatorname{sd} 2 ; \operatorname{tg}(k d r l$ :EGFP) S843 double transgenic embryos were anesthetized with $0.016 \%$ Tricaine (Sigma) at $2 \mathrm{dpf}$ and then submitted to 
image acquisition with a fluorescence or confocal microscope. The endogenous alkaline phosphatase (AP) activity was determined as previously described (33). Briefly, the embryos were fixed with 4\% PFA at room temperature (RT) for $2 \mathrm{~h}$, rinsed in PBS, and incubated overnight at $4^{\circ} \mathrm{C}$. Embryos were then incubated in $100 \% \mathrm{MetOH}$ for $2 \mathrm{~h}$ at RT, hydrated sequentially in PBS, and rinsed for $30 \mathrm{~min}$ in AP buffer $(100 \mathrm{mM}$ of Tris- $\mathrm{HCl} \mathrm{pH} 9.5,100 \mathrm{mM}$ of $\mathrm{NaCl}, 50 \mathrm{mM}$ of $\mathrm{MgCl} 2,1 \%$ Tween 20), and finally stained with NBT/BCIP diluted in AP buffer.

Staining for hemoglobinized red cells were achieved by incubating embryos in a solution containing O-dianisidine (Sigma) as described (34).

\section{Analysis of skeletal development}

For cartilage and bone staining (35), larvae at $5 \mathrm{dpf}$ were fixed in $4 \%$ PFA for $2 \mathrm{~h}$ at room temperature, washed three times in PBS for $5 \mathrm{~min}$, and rinsed in $50 \%$ ethanol for $10 \mathrm{~min}$. Embryos were stained overnight in the staining solution ( $0.02 \%$ Alcian blue, $0.5 \%$ Alizarine red, $40 \mathrm{mM}$ of $\mathrm{MgCl} 2$ in $70 \% \mathrm{EtOH})$. The next day, larvae were washed in clearing solutions $(20 \%$ glycerol and $0.25 \% \mathrm{KOH}, 50 \%$ glycerol and $0.25 \% \mathrm{KOH}$ ), rinsed in $85 \%$ glycerol/PBS and then submitted to image acquisition.

\section{TH quantification}

The quantification of TH levels was performed as previously described $(36,37)$. Approximately 100 larvae were homogenized in $0.1 \mathrm{~mL}$ of lysis buffer. Samples were disrupted for $10 \mathrm{~min}$ on ice by sonication and centrifuged at $13,000 \mathrm{rpm}$ for $10 \mathrm{~min}$ at $4^{\circ} \mathrm{C}$. The supernatants were collected, and the $\mathrm{T} 3$ and $\mathrm{T} 4$ contents (ng/g fish weight) were measured using specific enzyme-linked immunosorbent assay kits (Uscnlife) following the manufacturer's instructions.

\section{Image acquisition and statistical analysis}

Images were taken with a Leica MZFLIII epifluorescence stereomicroscope equipped with a DFC480-R2 digital camera and the LAS imaging software (Leica). Confocal microscopy was performed on a Nikon C2+ confocal microscope (Nikon), equipped with a $20 \times$ objective. Images were processed using Adobe Photoshop software. All data are shown as means $\pm S D$ or percentages. Student's $t$-test was used for comparison of differences between groups. A $p$-value of $<0.05$ was considered statistically significant. All the analyses were conducted with GraphPad Prism v4.0 (GraphPad).

\section{Results}

$h T R \alpha$ variants affect zebrafish embryonic development that can be variably overcome by high T3 doses

Wild-type zebrafish embryos at the one- to two-cell stage were injected with $80 \mathrm{pg} / \mathrm{embryo}$ of each hTR $\alpha$ mRNA. The injection of wild-type $\mathrm{hTR} \alpha$ has no evident effects on zebrafish development, whereas the hTR $\alpha$ mutants D211G (10), A263V (5), A382PfsX7 (3), E403X (1), and F397fs406X (4) cause relevant defects. After $6 \mathrm{hpf}$, the injected embryos were treated with the control vehicle (DMSO) or a T3 dose that was previously found to overcome the diminished T3binding activity of mutant receptors $(20 \mu \mathrm{M}$ in the harvest water) (21). At $2 \mathrm{dpf}$, all injected embryos showed a series of morphological defects when compared with uninjected controls, which were categorized into three major groups: G1 embryos ( $2 \%$ of total; Supplementary Fig. S2B and B', E and $\mathrm{E}^{\prime}, \mathrm{H}$ and $\mathrm{H}^{\prime}, \mathrm{K}$ and $\mathrm{K}^{\prime}$, and $\mathrm{N}$ and $\mathrm{N}^{\prime}$ ) developing similarly to uninjected controls (A); G2 embryos (93\% of total) with several developmental alterations, including short body length, small eyes, skeletal abnormalities, hydrocephalus, and cardiac edema (Supplementary Fig. S2C and $\mathrm{C}^{\prime}, \mathrm{F}$ and $\mathrm{F}^{\prime}$, I and $\mathrm{I}^{\prime}, \mathrm{L}$ and $\mathrm{L}^{\prime}$, and $\mathrm{O}$ and $\mathrm{O}^{\prime}$ ); and $\mathrm{G} 3(5 \%)$ embryos with dramatic morphological alterations leading to death by $4 \mathrm{dpf}$ (D and $\mathrm{D}^{\prime}, \mathrm{G}$ and $\mathrm{G}^{\prime}, \mathrm{J}$ and $\mathrm{J}^{\prime}, \mathrm{M}$ and $\mathrm{M}^{\prime}$, and $\mathrm{P}$ and $\mathrm{P}^{\prime}$ ). Treatment with T3 could revert the abnormal phenotypes only in embryos injected with $\mathrm{hTR} \alpha \_\mathrm{D} 211 \mathrm{G}$ and $\mathrm{hTR} \alpha$ A263V transcripts, as shown by the significant increase in the rate of G1 embryos ( $+79 \%$ and $+81 \%$ vs. controls, respectively; Supplementary Fig. S2B'-D' and $\left.E^{\prime}-G^{\prime}\right)$. Conversely, no significant modifications were induced by $\mathrm{T} 3$ in embryos injected with the truncated hTR $\alpha \_A 382 P f s X 7\left(\mathrm{H}^{\prime}-\mathrm{J}^{\prime}\right), \mathrm{hTR} \alpha \_E 403 \mathrm{X}$

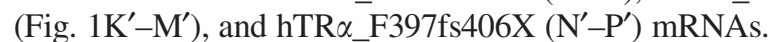

The mutant hTR $\alpha$-injected (mut_hTR $\alpha$ ) embryos exhibited blood circulatory defects with blood stasis in the head and the tail regions (Fig. 1). About $80-90 \%$ of vehicle-treated mut_hTR $\alpha$ embryos showed a severely defective blood circulation (Fig. 1A, D-M). Only the hTR $\alpha \_D 211 \mathrm{G}-$ and hTR $\alpha$ A263V-injected embryos showed a significant recovery $(+87 \%$ and $+83 \%$ over the baseline, respectively) after T3 supplementation (Fig. 1A, $\mathrm{D}^{\prime}-\mathrm{M}^{\prime}$ ).

\section{$h T R \alpha$ variants perturb development and function of zebrafish heart}

The in vivo analysis of circulation defects observed in all mut_hTR $\alpha$ embryos prompted the investigation of their heart morphology by a molecular approach, through WISH with the cardiac-specific marker cardiac myosin light chain 2 (cmlc2; Fig. 2). At $2 \mathrm{dpf}$, the control fish had a normal $\mathrm{S}$-shaped heart, with the ventricle positioned on the right of the atrium, indicating a correct D-looping process (Fig. 2A). Heart morphology was unaffected in a minority of the mut_hTR $\alpha$ embryos (Fig. 2B and F), but most of these embryos displayed a moderate phenotype with impaired looping (Fig. 2C), or absence of looping with a completely linear heart tube (Fig. 2D), or a reversed heart looping with the ventricle on the left of the atrium (Fig. 2E). Additionally, all mut_hTR $\alpha$ embryos exhibited a 20-25\% reduction in heart rate compared with controls (Fig. 2G). Only the hTR $\alpha_{-}$ $\mathrm{D} 211 \mathrm{G}$ and $\mathrm{hTR} \alpha \_\mathrm{A} 263 \mathrm{~V}$ variants positively responded to T3 supplementation, with restoration of normal cardiac development and contractility (Fig. 2F and G).

\section{$h T R \alpha$ variants alter vascular development and erythropoiesis of zebrafish embryos}

The $\operatorname{tg}($ gatal:dsRed)sd2; $\operatorname{tg}(k d r l: E G F P) S 843$ double transgenic line (22), in which endothelial cells are labeled in green and erythrocytes in red, was used to study vascular development. At $2 \mathrm{dpf}$, the mut_hTR $\alpha$ embryos had moderate to severe defects (Fig. 3). The mut_hTR $\alpha$ embryos with a moderate vascular phenotype were characterized by the reduction of the cardinal vein $(\mathrm{CV})$ plexus and presence of all intersomitic vessels (ISVs) along the trunk and tail, but with a partially altered patterning (Fig. 3K and L vs. Fig. 3C and D). 

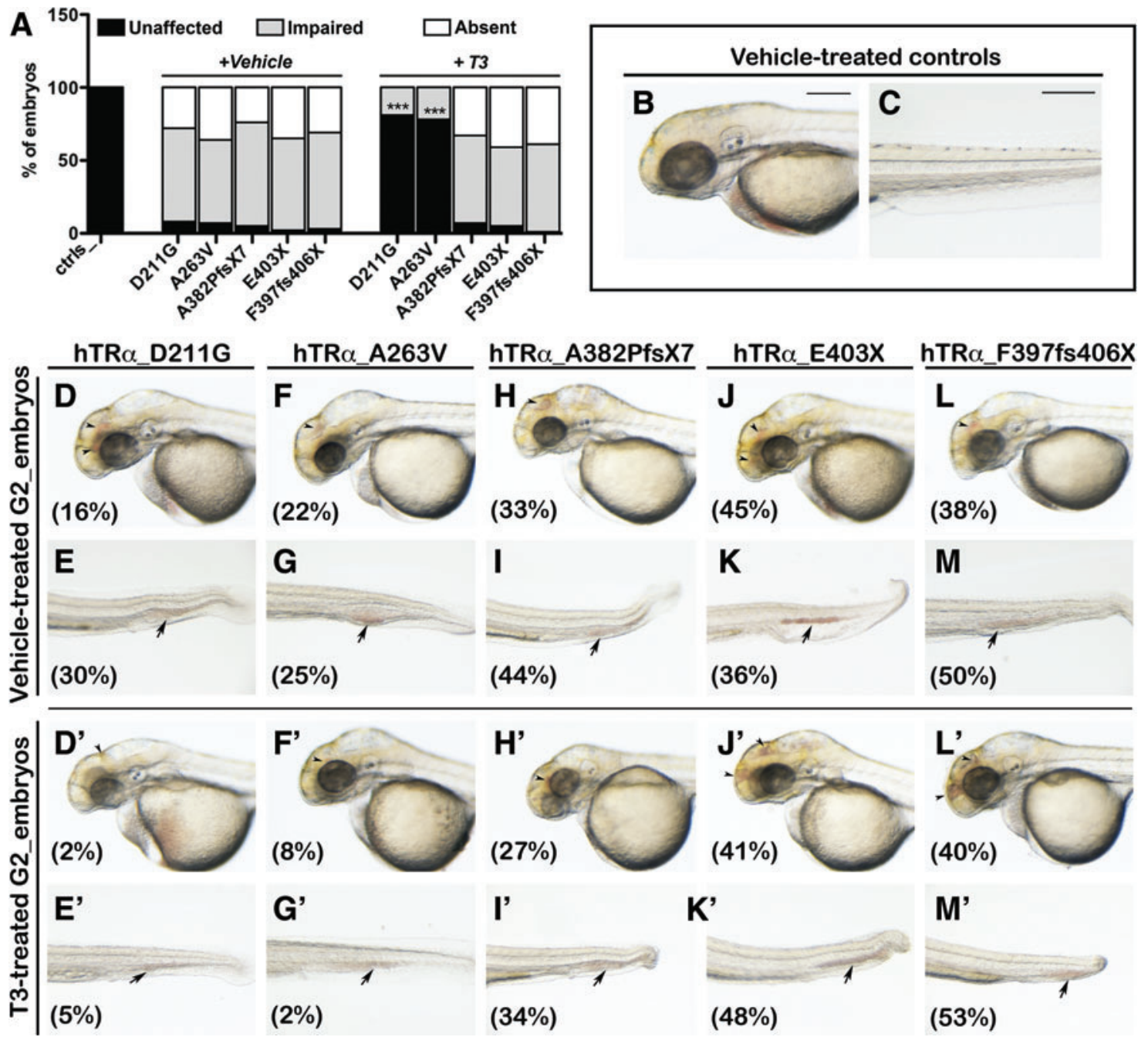

hTRQ_F397fs406X
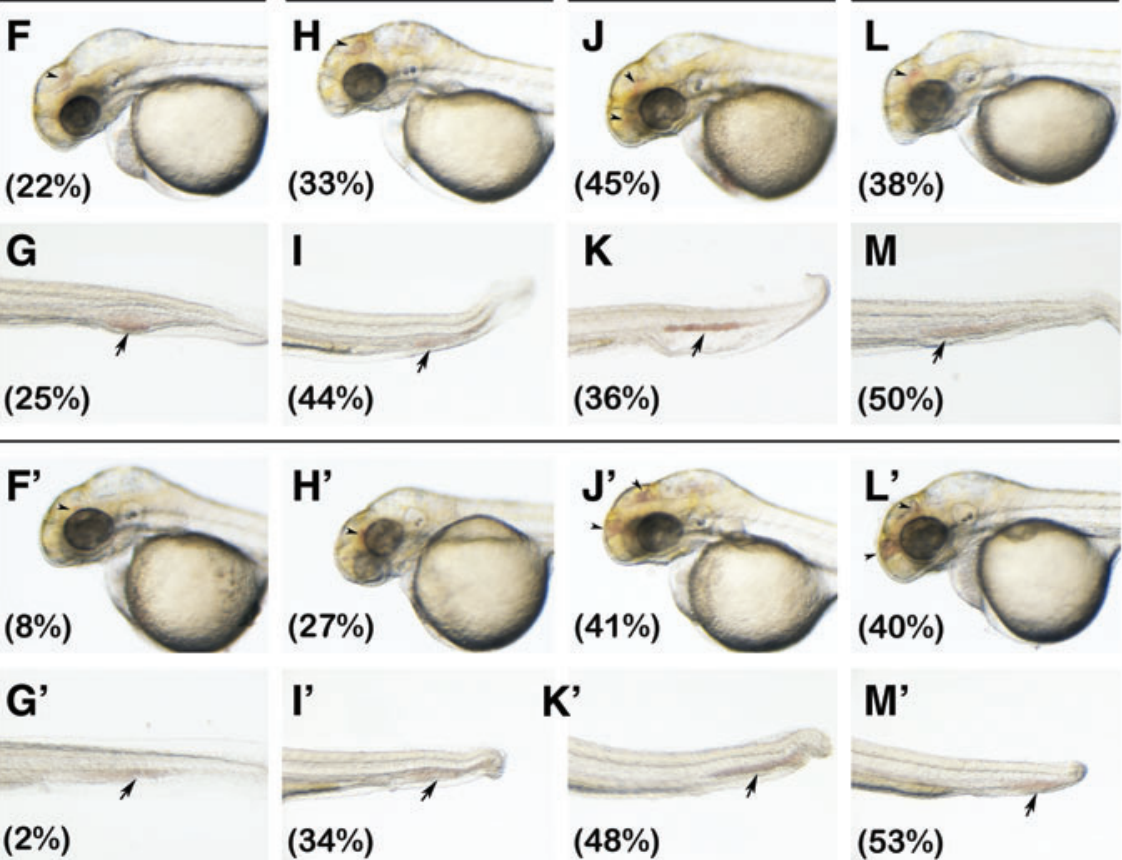

(34\%)

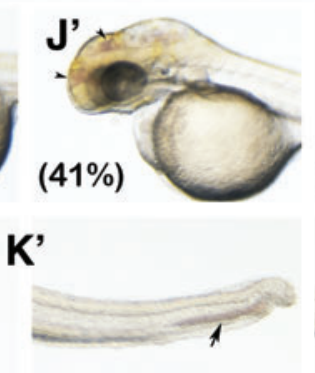

$(48 \%)$

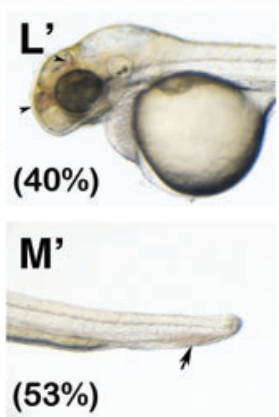

FIG. 1. Analysis of blood circulation of human thyroid hormone receptor alpha (hTR $\alpha$ )-injected embryos. At 2 days post fertilization (dpf), the embryos injected with the hTR $\alpha$ variants displayed variable defects in blood circulation, including unaffected circulation, impaired circulation, or absent circulation. (A) The frequency of controls or injected embryos that displayed those defects after vehicle or T3 treatment. $p<0.001$ versus vehicle-treated embryos (***). (B) and (C) Head and tail images of control fish (lateral view). Scale bar: $100 \mu \mathrm{m})$. (D-L) and $\left(\mathbf{D}^{\prime}-\mathbf{L}^{\prime}\right)$ Cerebral hemorrhage (arrow head) in vehicle- or T3-treated embryos. (E-M) and $\left(\mathbf{E}^{\prime}-\mathbf{M}^{\prime}\right)$ Blood stasis in the tail (arrow) in vehicle- or T3-treated embryos. The frequency of embryos for each phenotype is reported in parentheses. Color images available online at www.liebertpub.com/thy

The ISVs of these injected embryos reached the dorsal longitudinal anastomotic vessel (DLAV), but they appeared thin and straight, not following the normal shape of somites (Fig. 3L). In injected embryos with a severe vascular phenotype, the posterior ISVs displayed aberrant branching, and the prematurely truncated vessels did not connect to the DLAVs (Fig. 30 and P). Notably, moderate or severe defects in ISVs were observed in mut_hTR $\alpha$ embryos with both normal (Fig. 3I and $\mathrm{K}$ ) and curved tails (Fig. 3M and O), suggesting that vascular alterations were likely caused by abnormalities of angiogenesis. The rate of embryos with the illustrated defects is reported in the histogram (Fig. 3Q). Consistent with previous findings after $\mathrm{T} 3$ treatment, the vast majority of the D211G- and A263V-injected embryos recovered normal development of the trunk and tail vasculature (Fig. 3F and G) with well-defined and intact ISVs (Fig. 3H). Additionally, attention was focused on the development of the subintestinal vein (SIV), which delivers blood to the di- gestive tract of the larva $(38,39)$. The SIV plexus, at around $3 \mathrm{dpf}$, appeared as a basket of predominantly venous angiogenic vessels, extended on the large surface of the yolk ball. The vast majority of the mut_hTR $\alpha$ embryos had an impaired (Supplementary Fig. S3G-I) or absent (J-L) formation of both the left and right SIV plexus compared with controls (Supplementary Fig. S3A-C). The fish injected with the missense variants D211G and A263V (M) showed significant normalization in the development of the SIV plexus (D-F) after T3 treatment. Taken together, these results indicate a central role of hTR $\alpha$ during angiogenic blood-vessel formation.

Interestingly, a large number $(>80 \%)$ of the vehicle-treated mut_hTR $\alpha$ embryos also showed blood stasis at the level of the caudal vein plexus and a diminished red staining consistent with a reduced amount of circulating erythrocytes at $2 \mathrm{dpf}$ (Figs. 1 and 3J and N).

Defects of erythrocyte numbers observed in vivo were further investigated by the staining of hemoglobin with 

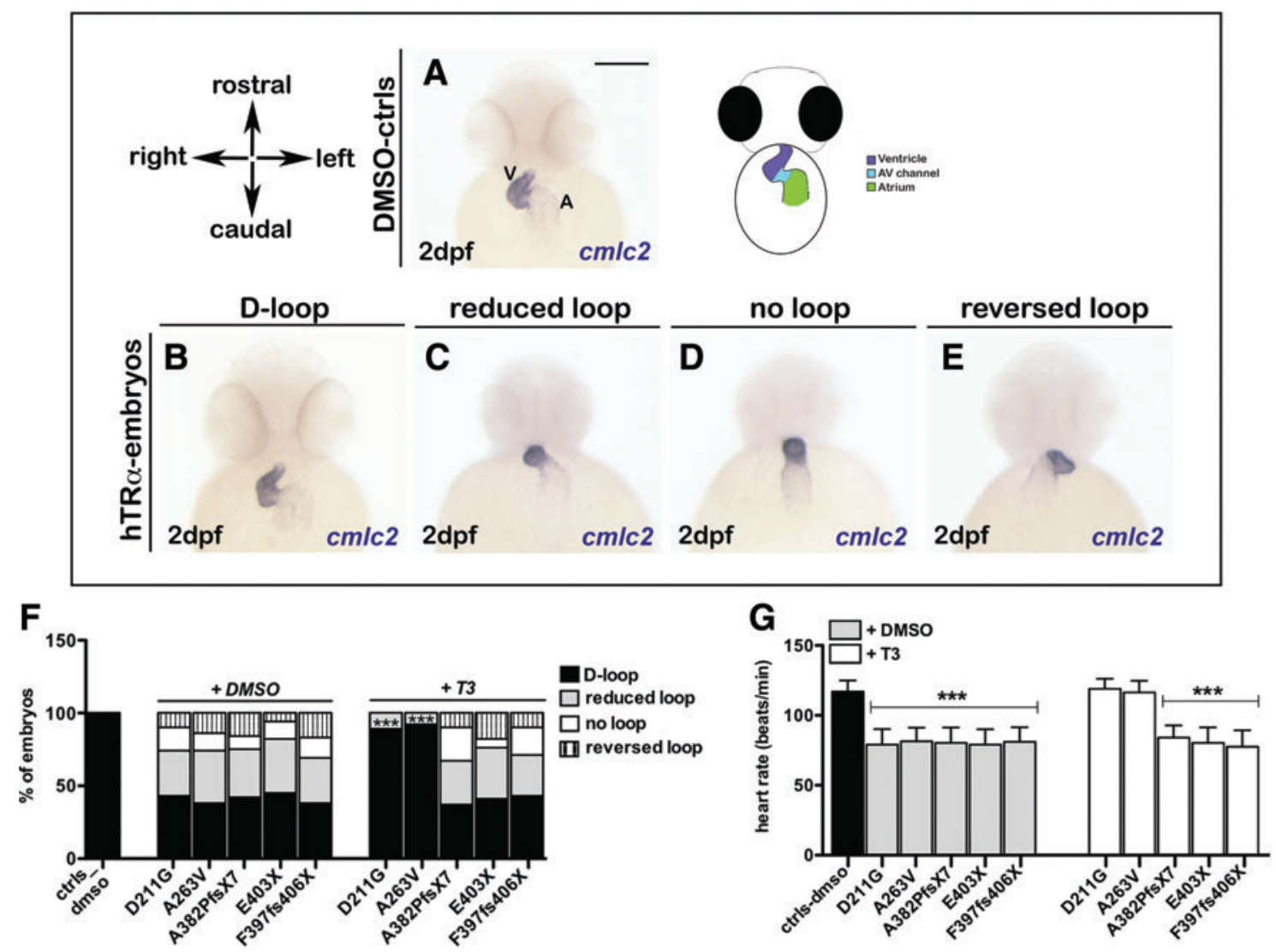

FIG. 2. Analysis of heart looping in hTR $\alpha$-injected embryos. Analysis of $c m l c 2$ expression by whole mount in situ hybridization (WISH) was performed on controls and hTR $\alpha$-injected embryos followed by treatment with vehicle or triiodothyronine (T3) at $2 \mathrm{dpf}$. Scale bar in (A): $(100 \mu \mathrm{m})$. The heart position in injected embryos was scored as D-loop (normal; B), incomplete loop $(\mathbf{C})$, no loop $(\mathbf{D})$, and reversed loop $(\mathbf{E})$ when compared to controls at 2 dpf $(\mathbf{A})$. V, ventricle; A, atrium. All embryo images were acquired in frontal view, head to the top. The detailed representation of the developing heart at $2 \mathrm{dpf}$ is reported in the drawing image. (F) The histogram shows the ratio of controls or hTR $\alpha$-injected embryos (vehicle or T3 treated) with the different heart defects. $* * * p<0.001$ versus vehicle-treated embryos. $(\mathbf{G})$ Heart rate of vehicle- or T3-treated $\mathrm{hTR} \alpha$-injected embryos compared to controls at $2 \mathrm{dpf}$. $* * * p<0.001$ versus controls. Color images available online at www.liebertpub.com/thy

F4 $o$-dianisidine (40) at 2 and 5 dpf (Fig. 4). Hypochromia was evident at $2 \mathrm{dpf}$, when $>90 \%$ of the mut_hTR $\alpha$ embryos exhibited severe reductions in circulating erythrocytes (Fig. 4E and $\mathrm{F}, \mathrm{G}$ and $\mathrm{H})$, that were instead detectable in the heart $(\mathrm{H})$, the sinus venosus (SV), the main axial vessels (DA and PCV), and in the CV plexus in control embryos (Fig. 4A and B). At $5 \mathrm{dpf}, o$-dianisidine clearly stained the erythrocytes localized in the jugular veins (JV), in the aortic arches (AA), and in the heart of controls (Fig. 4J), whereas the injection of the hTR $\alpha$ mutant transcripts resulted in a dramatic decline in mature erythrocytes (Fig. 4K, L, and M). In 15-30\% of these cases, the remaining erythrocytes appeared concentrated in the head (Fig. 4L) or tail regions (Fig. 4M). Again, only the embryos injected with the missense $\mathrm{hTR} \alpha$ variants showed an almost complete rescue of the hematological phenotype upon T3 treatment (Fig. 4I and N).

\section{$h T R \alpha$ mutations affect motorneuron development of zebrafish embryos}

It was observed that all injected embryos showed progressive motility defects, starting with reduced spontaneous movements at $1 \mathrm{dpf}$ and leading to a severe or complete inability of autonomous swimming in later stages. The zebrafish spinal cord has both early-developing primary motorneurons, which arise during the first day of zebrafish development, and secondary motorneurons that develop later on. The latter axons sprout several hours after the primary motor growth cones have extended to the periphery $(41,42)$. At 28 hpf, znp1 labeled the primary motorneurons (PMN) and their axonal projections (AP) that innervated specific parts of the adjacent myotomes in control fish (Fig. 5A and $\mathrm{A}^{\prime}$ ). In contrast, axonal pathfinding was impaired in mut_hTR $\alpha$ embryos with a moderate to severe disorganization of motorneurons that appear misorientated, or truncated (Fig. 5BD), but this was accompanied by a normal development of the muscle fibers (Fig. 5B'-D'). At $52 \mathrm{hpf}$, by performing IHC with a specific antibody for secondary motorneurons (zn-5), it was observed that secondary motorneuron axons were also affected in mut_hTR $\alpha$ embryos (Fig. 5E-H). In $>85 \%$ of these embryos, axons of the secondary motorneurons (SMN) stalled at the distal point of the common path, failing to reach the horizontal myoseptum (HMS; Fig. 5F) or were totally absent (Fig. 5G and H). Consistent with previous data, T3 

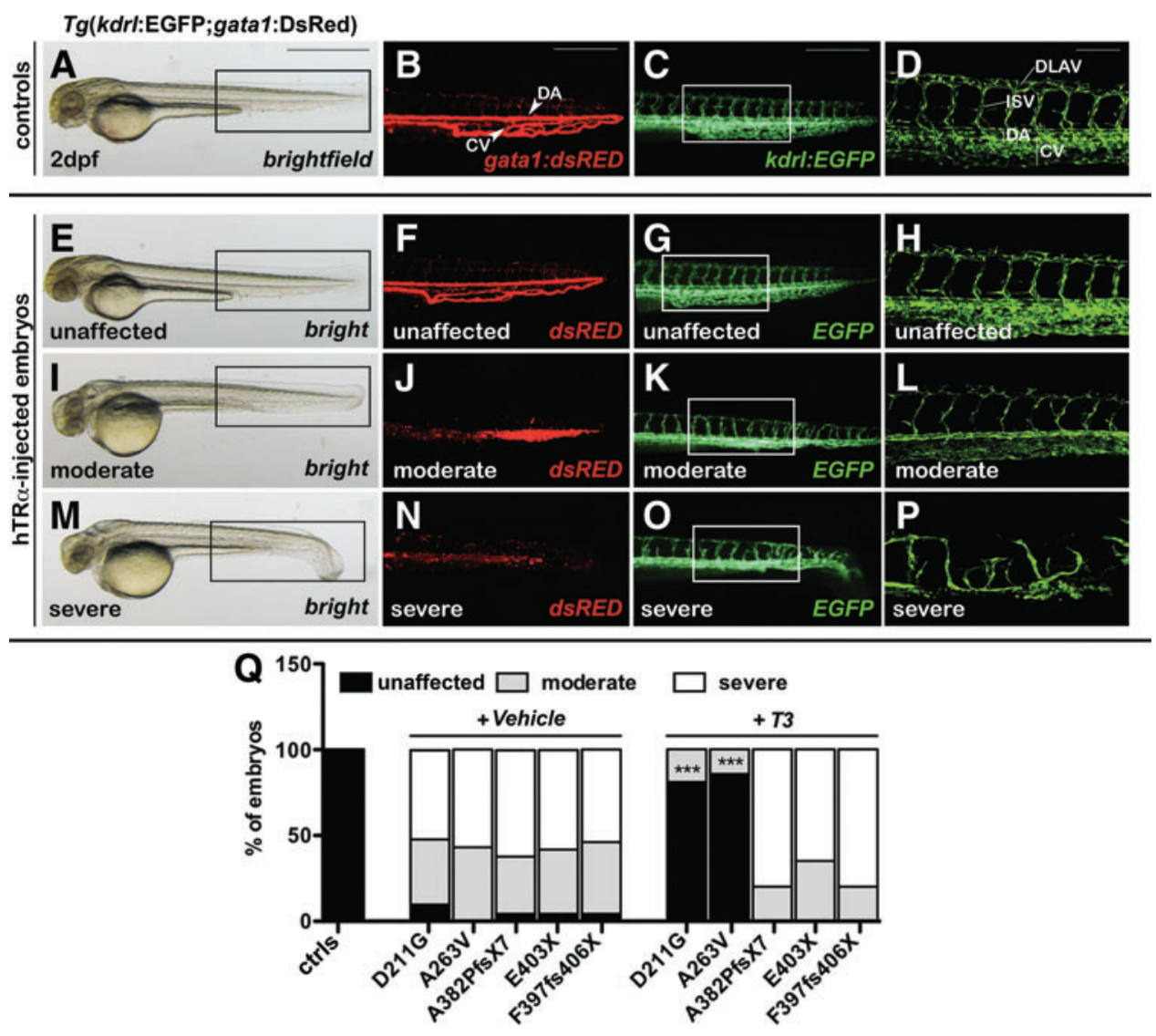

FIG. 3. Analysis of vasculature development in hTR $\alpha$-injected embryos. The double transgenic line $\operatorname{tg}($ gatal:dsRed $)$ sd 2 ; $\operatorname{tg}(k d r l$ :EGFP)S843 was used to visualize the vascular architecture and the blood circulation at 2 dpf. (A), (E), (I), and (M) Brightfield images of controls and hTR $\alpha$-injected embryos displaying normal, moderate, or severe phenotype (in lateral view, head to the left). (B), (F), (J), and (N) Magnification of the tail, in which the red fluorescent dsRed marks the circulating erythrocytes in the dorsal aorta (DA) and cardinal veins (CV) of the plexus (arrows). (C), $(\mathbf{G}),(\mathbf{K})$, and $(\mathbf{O})$ and confocal magnification in $(\mathbf{D}),(\mathbf{H}),(\mathbf{L})$, and $(\mathbf{P})$ Green fluorescence signal localized in endothelial cells of the DA, CV, and intersegmental vessels (ISV) and dorsal longitudinal anastomotic vessel (DLAV) of the trunk. Scale bars in (A): $50 \mu \mathrm{m}$; (B) and (C): $100 \mu \mathrm{m}$ ); and (D): $250 \mu \mathrm{m}$ (objective 20x). (Q) The histogram shows the ratio of controls or hTR $\alpha$-injected embryos (vehicle or T3 treated) with normal, moderate, or severe vascular defects. $*_{* *}^{*} p<0.001$ versus vehicle-treated embryos. Color images available online at www.liebertpub.com/thy

treatment significantly improved motorneuron development only in embryos injected with the missense hTR $\alpha \_D 211 \mathrm{G}$ and_A263V transcripts (I and J).

\section{$h T R \propto$ variants perturb the development of cartilage and bones of zebrafish larvae}

In mut_hTR $\alpha$ embryos, most of the pharyngeal and neurocranium cartilage elements were malformed (Fig. 6G-L vs. $6 \mathrm{~A}-\mathrm{C})$. Indeed, the vast majority of the vehicle-treated embryos presented with moderate to severe phenotypes (Fig. 6M). In mut_hTR $\alpha$ embryos with a moderate phenotype, the first mandibular arch (Meckel's cartilage) appeared slightly malformed, whereas the second arch (ceratohyal cartilage) was unevenly formed (Fig. 6G-H), and the five ceratobranchial arches were largely lacking (Fig. 6H). In all severely affected embryos, all cartilaginous components were completely absent (Fig. 6J-L). Severe morphological phenotypes were also observed in bone mineralization. Under basal conditions, most of the mut_hTR $\alpha$ embryos showed an impaired or absent development of the brachiostegal rays and operculum (Fig. 6G and $\mathrm{H}$ and $\mathrm{J}$ and $\mathrm{K}$ ) in comparison with controls (Fig. 6A and B). In contrast, a strong reduction or absence of mineralization of the cleithrum and notochord was seen only in the mut_hTR $\alpha$ embryos with a severe phenotype (Fig. 6J and L). Consistent with previous results, T3 treatment effectively reverted the pathological skeletal phenotype only in the embryos injected with the hTR $\alpha$ D211G and hTR $\alpha \_A 263 V$ transcripts (Fig. 6D-F and M).

\section{Injection of the $h T R \alpha$ variants recapitulates the biochemical features of RTHo}

The TH sensitivity at $5 \mathrm{dpf}$ - the stage in which the zebrafish gland produces T4, and the development of the HPT axis is complete and responds to endogenous TH levels (43) — was explored. Under basal conditions, the mut_hTR $\alpha$ larvae presented normal levels of the hypothalamic trh (Fig. 7D, G, J, M, and P) and pituitary tshba (Fig. 7E, H, K, N, and Q), but displayed a low number of T4-producting follicles (Fig. 7F, I, L, O, and R) when compared with controls (Fig. 7A-C). The administration of $20 \mu \mathrm{M}$ of $\mathrm{T} 3 \mathrm{led}$ to the 

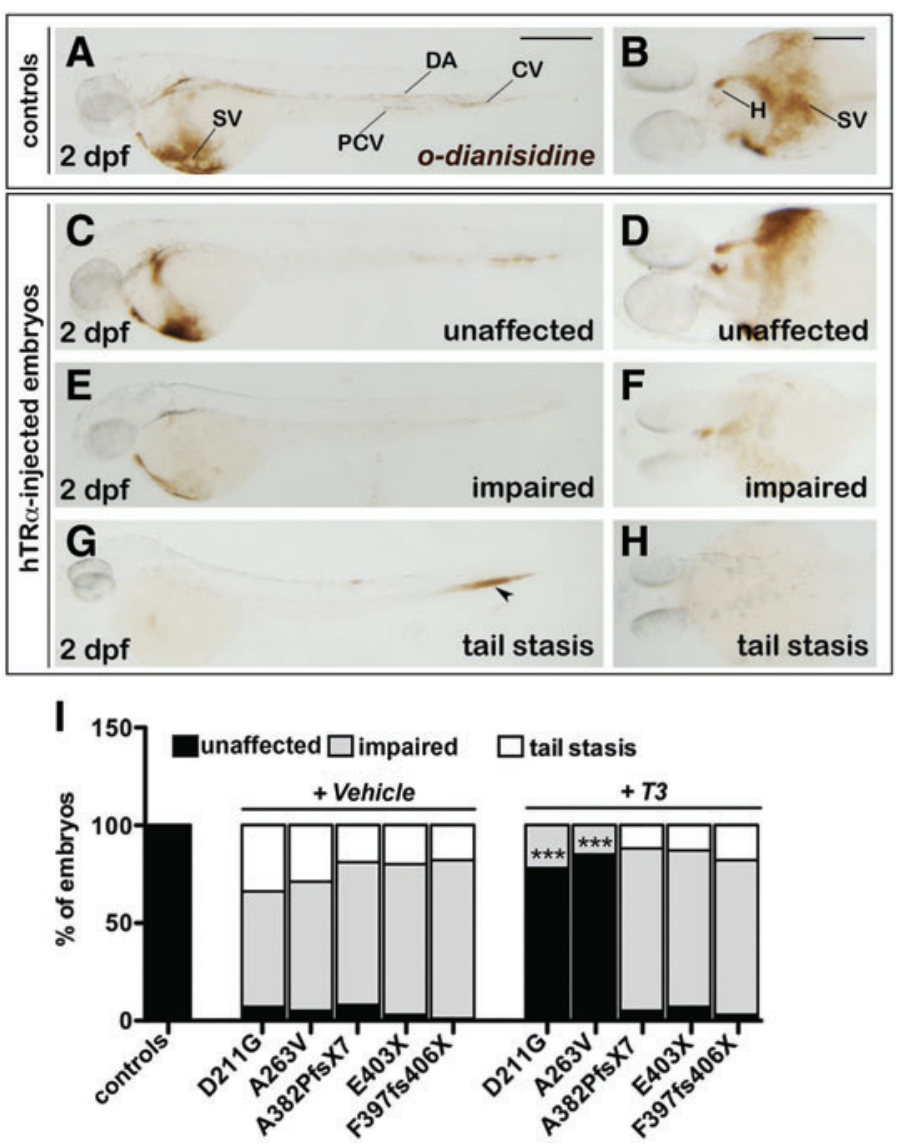
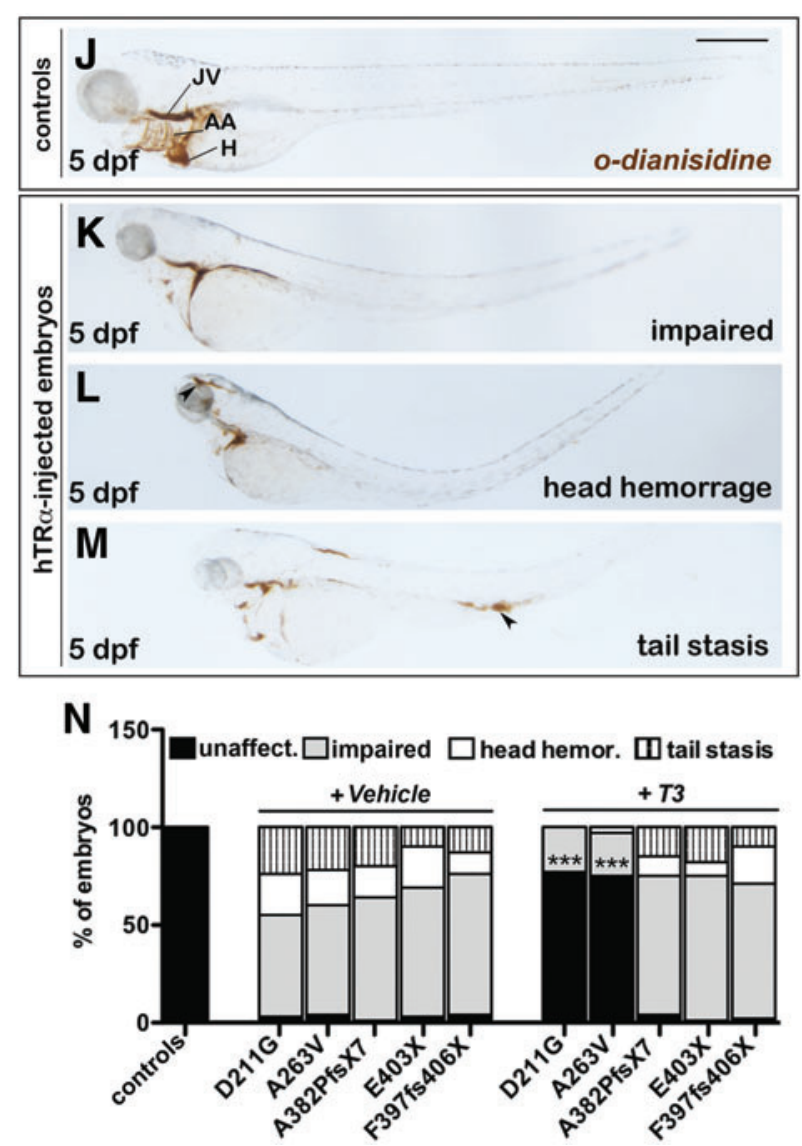

FIG. 4. Analysis of erythropoiesis in hTR $\alpha$-injected embryos. (A) and (B) and (C) and (D) $O$-dianisidine staining in controls and normal embryos at $2 \mathrm{dpf}$ in lateral and in ventral views. The circulating erythrocytes are visible in the heart (H), sinus venosus $(\mathrm{SV})$, in the major vessels (dorsal aorta $[\mathrm{DA}]$ and posterior cardinal vein [PCV] and the caudal vein [CV] plexus). Scale bars in (A): $50 \mu \mathrm{m}$; and (B): $100 \mu \mathrm{m}$. (E) and (F) Reduced red blood cells in the whole body. (G) and (H) Absent staining in the cardiovascular system and tail stasis. (J) Mature erythrocytes in $5 \mathrm{dpf}$ control larvae observed in the jugular veins (JV), aortic arches (AA), and the heart (H). Scale bar in $(\mathbf{J}): 50 \mu \mathrm{m}$. (K) hTR $\alpha$-injected embryos that present a dramatic reduction of red blood cells. (L) and (M) Injected embryos showing a reduced staining in combination with head hemorrhages or tail stasis (arrowheads). The ratio of embryos with these defects is reported in (I) and (N). ***p<0.001 versus vehicle-treated embryos. Color images available online at www.liebertpub.com/thy

suppression of trh and tshba transcripts (Fig. 7D', G', $\mathrm{J}^{\prime}, \mathrm{M}^{\prime}$, and $\left.\mathrm{P}^{\prime}\right)$ together with an expected further reduction of $\mathrm{T} 4-$ positive follicles (Fig. $7 \mathrm{~F}^{\prime}, \mathrm{I}^{\prime}, \mathrm{L}^{\prime}, \mathrm{O}^{\prime}$, and $\mathrm{R}^{\prime}$ ). The measurement of the $\mathrm{T} 4$ content gave consistent results (Fig. 7S). Conversely, T3 levels were significantly increased in hTR $\alpha$ injected larvae in both basal $(p<0.01)$ and T3 conditions $(p<0.001)$. Importantly, the changes observed in TH levels of mut_hTR $\alpha$ larvae after T3 treatment ( $p<0.01$ vs. vehicle) together with the suppression of $t r h, t \operatorname{sh} b a$, and T4 reflected the conservation of the TH sensitivity of the HPT axis.

Therefore, the ability of human D211G and E403X variants on the activity of zebrafish receptors was tested using a

SF4 published T3-dependent activation assay (1) (Supplementary Fig. S4). As expected, the hTR $\alpha$ _D211G and_E403X plasmids did not activate the TH-responsive gene, either in the absence or in the presence of $10 \mathrm{nM}$ of $\mathrm{T} 3$ (A). Furthermore, when coexpressed, both variants strongly inhibited the T3 transcriptional activation of the wild-type human and zebrafish TRs in a dominant negative manner (Supplementary Fig. S4B). Interestingly, both D211G (-30\%) and E403X (-27\%) exhibited a less pronounced interference on wild-type activity when co-transfected with the zTR $\beta 2$ plasmid (Supplementary Fig. S4B). Since TR $\beta 2$ is one of the major contributors in the regulation of the HPT axis, particularly on $\mathrm{TSH} \beta$ expression (44), these data may explain the conserved response of $t s h \beta$ and trh transcripts observed in mut_hTR $\alpha$ embryos in vivo.

The high T3/T4 ratio observed in the mut_hTR $\alpha$ embryos may be explained by an altered TH metabolism, as previously described (21). As reported in Supplementary Fig. S5, at $2 \mathrm{dpf}$, the expression of pituitary dio2 was increased in both vehicle and T3-treated mut_hTR $\alpha$ embryos (D and $D^{\prime}, G$ and $\mathrm{G}^{\prime}, \mathrm{J}$ and $\mathrm{J}^{\prime}, \mathrm{M}$ and $\mathrm{M}^{\prime}$, and $\mathrm{P}$ and $\mathrm{P}^{\prime}$ vs. control $\mathrm{A}$ and $\mathrm{A}^{\prime}$ ). At $1 \mathrm{dpf}$, all vehicle-treated mut_hTR $\alpha$ embryos presented a reduced expression of both dio $3 a$ in the brain region $(\mathrm{E}, \mathrm{H}, \mathrm{K}$, $\mathrm{N}$, and $\mathrm{Q}$ ) and diozb in the pronephros (F, I, L, O, and R). In responses to $\mathrm{T} 3$ treatment, only the embryos injected with $\mathrm{hTR} \alpha \_\mathrm{D} 211 \mathrm{G}$ and $\mathrm{hTR} \alpha \_\mathrm{A} 263 \mathrm{~V}$ transcripts recovered a normal expression of dio $3 a$ and $\operatorname{dio} 3 b\left(\mathrm{E}^{\prime}\right.$ and $\mathrm{F}^{\prime}$ and $\mathrm{H}^{\prime}$ and $\left.I^{\prime}\right)$. These results have been also confirmed by qRT-PCR. Remarkably, changes in TH metabolism observed at $2 \mathrm{dpf}$ (for dio2) and at $1 \mathrm{dpf}$ (for dio3a and dio3b) persisted in the mut_hTR $\alpha$ larvae at $5 \mathrm{dpf}(\mathrm{S}-\mathrm{V})$. 

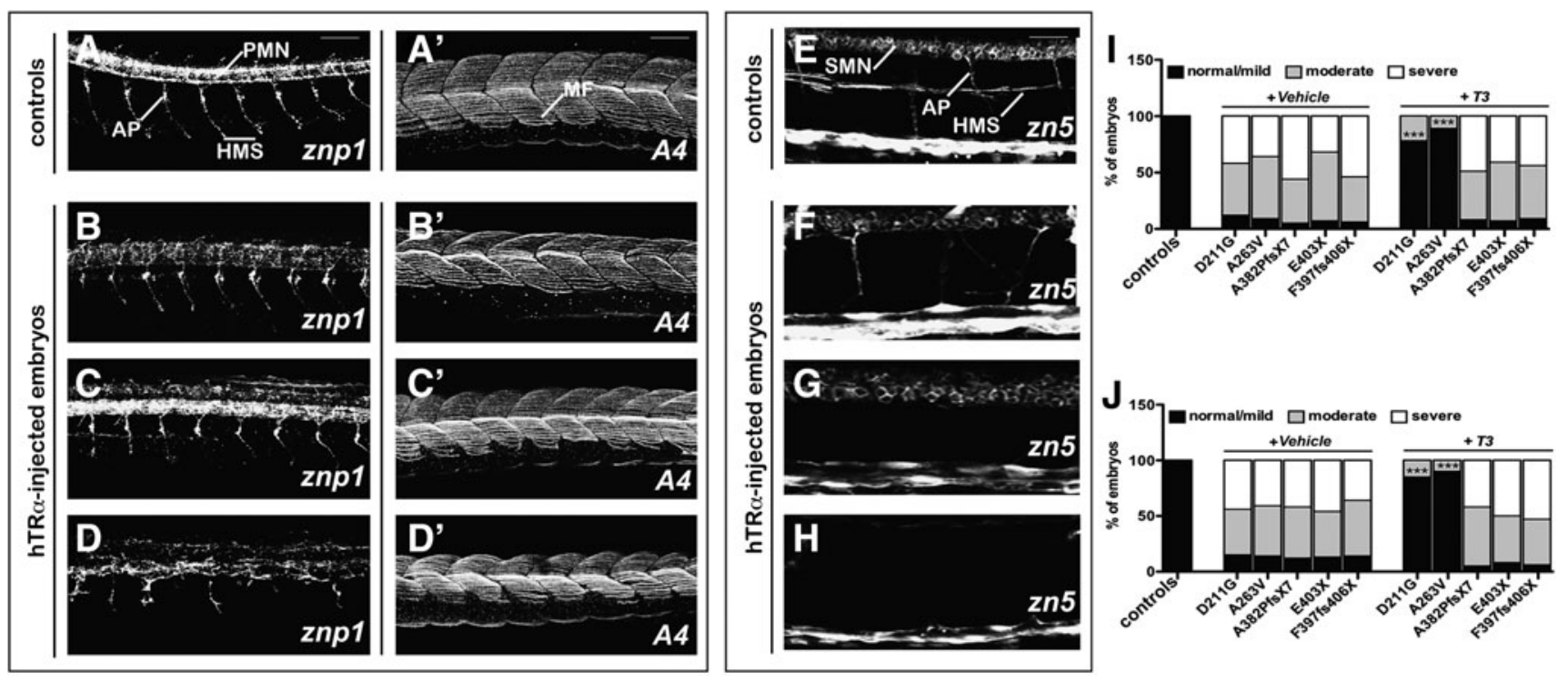

FIG. 5. Analysis of development of motorneurons in hTR $\alpha$-injected embryos. Left: Staining of controls of the znp1 monoclonal antibody at 28 hours post fertilization (hpf). Zpn1 marks the primary motorneurons (PMN), visible at the level of the spinal cord, and their axonal projections (AP) that extend ventrally and reach the horizontal myoseptum (HMS) (A). The development of muscle fibers (MF) visualized by anti-myosin antibody (A4) of controls is shown in $\left(\mathbf{A}^{\prime}\right)$. Scale bars in (A) and (A'): $250 \mu \mathrm{m}$ (objective $20 \times$ ). The hTR $\alpha$-injected embryos show a mild reduction of SCN and NMP (B), moderate defects on PMN and AP (C), or severe abnormalities in primary motorneurons (D), in the presence of normal muscle development $\left(\mathbf{B}^{\prime}, \mathbf{C}^{\prime}\right.$, and $\left.\mathbf{D}^{\prime}\right)$. The ratio of embryos belonging to these three major classes is reported in $(\mathbf{I})$. $* * * p<0.001$ versus vehicle-treated embryos. Right: Staining of controls at $52 \mathrm{hpf}$ with the zn5 monoclonal antibody. (E) Confocal acquisition of controls in which the secondary motorneurons (SMN) and their axonal projections (AP) that extend to the HMS are visible. Scale bars in (E): $250 \mu \mathrm{m}$ (objective 20×). The hTR $\alpha$-injected embryos showed mild alterations of SMN $(\mathbf{F})$, moderate defects with delayed or absent development of SMN $(\mathbf{G})$, or a severe reduction or absence of both SMN and AP $(\mathbf{H})$. The ratio of embryos these defects is reported in $(\mathbf{J}) . * * * p<0.001$ versus vehicle-treated embryos.

\section{Discussion}

The present work took advantage of the previously described interchangeability between the human and zebrafish $\mathrm{TR} \alpha$ proteins (21) to generate a simplified "tailor-made" in vivo model to study the pathological consequences of human THRA variants at the various tissue levels. The phenotypic consequences induced by several human THRA variants were analyzed, including two missense (D211G (10), A263V (5)) and three truncated (A382PfsX7 (3), E403X (1), and F397fs406X (2)) hTR $\alpha$ forms, forcing their expression by direct mRNA microinjection in zebrafish one- to two-cell embryos, as recently done with the human mutant transcripts found in patients with dynaminopathies (45). The embryos injected with $\mathrm{hTR} \alpha$ mutants underwent profound morphological, neurological, cardiovascular, hematological, skeletal, and biochemical alterations reminiscent of RTH $\alpha$ in humans. An efficient rescue of the disease phenotypes was always seen upon the addition of a high T3 concentration in the harvesting water only in embryos injected with the two missense variants, which are partially resistant to T3, but not with the completely refractory truncation mutations (110,21). Therefore, these findings support the view that the observed fish phenotypes are specifically caused by the DN activity exerted by hTR $\alpha$ mutants on zTRs, and that this may constitute a simplified model to study the functional consequences of hTR $\alpha$ mutants in vivo.

Interestingly, this model recapitulates the biochemical abnormalities described in $\mathrm{RTH} \alpha$ cases, confirming that the disproportionately raised T3/T4 ratio is the consequence of the combination of reduced levels of dio3, whose expression is known to be regulated by TR $\alpha 1$ (46), and raised dio 2 expression and activity. Both these modifications represent suitable responses to the impaired $\mathrm{TH}$ action at the tissue level (21). Consistent with data reported in patients with $\mathrm{RTH} \alpha$, and in contrast to the high TSH levels found in several murine models (12-20), the expression of the different hTR $\alpha$ variants caused modifications of TH levels in presence of normal expression of $t r h$, $t s h b a$, and $t g$. Furthermore, the sensitivity of the HPT axis of the injected embryos was well conserved, since they properly responded to exogenous administration of T3, thus allowing the presented model to recapitulate human $\mathrm{RTH} \alpha$ also at the biochemical level. The lack of an increased resistance to T3 in the hypothalamus and pituitary despite the unrestricted expression of $h \mathrm{TR} \alpha$ may be due to intrinsic properties of the endogenous $\operatorname{TR} \alpha$ and $\operatorname{TR} \beta$, as previously described in knock-in mice (47). Consistently, the activity of the zTR $\beta 2$ is only partially disturbed by both missense and truncated $\mathrm{hTR} \alpha$ variants also in vitro, suggesting a minor interaction between these two isoforms. Nevertheless, only the TR $\beta$ s (as homodimers or heterodimers with RXR) appear able to affect the transcription of the specific repertoire of target genes involved in TH feedback mechanism effectively.

Regarding the morphological and phenotypical consequences of the injected embryos, this study shows that the expression of all hTR $\alpha$ mutants resulted in variable defective embryonic development, confirming that the human mutant 

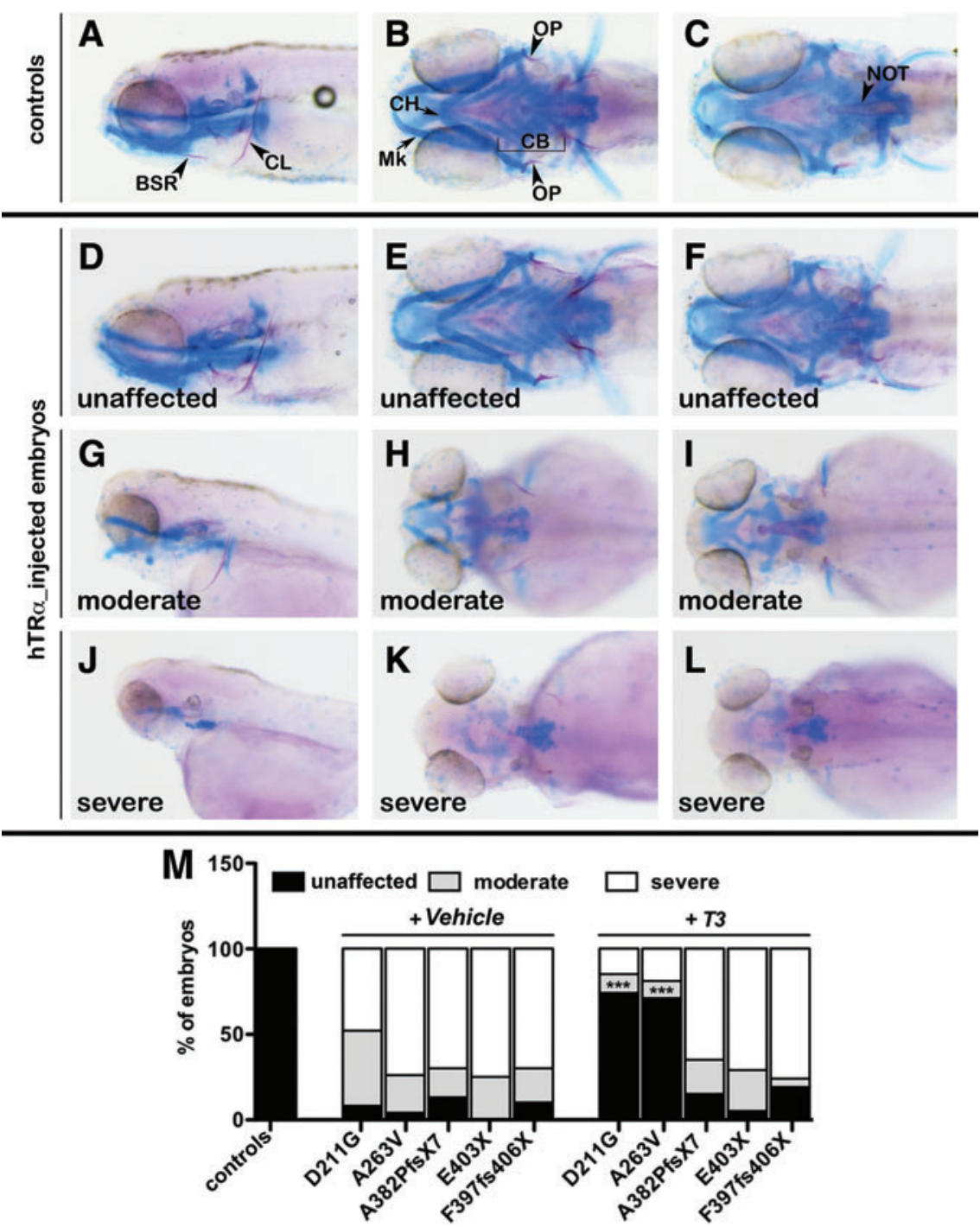

FIG. 6. Analysis of cartilage and bone development in hTR $\alpha$-injected larvae. At $5 \mathrm{dpf}$, all embryos were stained with Alician Blue (in blue) and Alizarine (in red) to visualize the formation of the head cartilage and the mineralization of bones, respectively. (A-C) Normal development of controls. The lateral view shows the brachiostegal rays (BRS) and cleithrum (CL; arrowheads); the ventral view illustrates the operculum (OP; arrowhead), the first and second mandibular arches (arrows), the Meckel's (Mk) and the ceratohyal $(\mathrm{CH})$ cartilages, and the five ceratobranchial arches (CB); the dorsal view reveals the mineralization of the notochord (NOT; arrowhead). Scale bars in (A-C): $100 \mu \mathrm{m}$. (D-F) hTR $\alpha$-injected embryos with normal development of both cartilages and bones. (G-I): hTR $\alpha$-injected embryos with defective formation of Mk and ch cartilages, absence of $\mathrm{cb}$ arches and reduced mineralization of brs and op. $(\mathbf{J}-\mathbf{L})$ : hTR $\alpha$-injected embryos with severe alterations in all cartilages and bones structures. (M) The histogram shows the frequencies of controls or hTR $\alpha$ injected embryos after vehicle or T3 treatment with a normal, moderate, or severe phenotype. $* * * p<0.001$ versus vehicle-treated $\mathrm{hTR} \alpha$ embryos. transcripts are able to interact with the functional zebrafish receptor in vivo (21). The hTR $\alpha$-injected embryos had hydrocephalus and cardiac edema associated with brain hemorrhages and blood stasis likely as a result of defective development or function of the cardiovascular system. The expression analysis of the specific cardiac marker $\mathrm{cmlc} 2$ by WISH revealed that the majority of the injected embryos at $2 \mathrm{dpf}$ presented several defects in heart looping, as a likely consequence of an altered heart tube bending associated with low heart rate at $2 \mathrm{dpf}$. These "altered looping" and bradycardia phenotypes indicate that the expression of genes involved in the differentiation of cardiac precursors, in the lateralization of the cardiac tube, or in the pacemaker functions (48-51) are also T3-TR $\alpha$ dependent in zebrafish. It is well documented that $\mathrm{T} 3$ plays a central role in the control of heart development and function, and that TR $\alpha 1$ is expressed in the myocardium, the atria, and the proximal conduction system (PVCS including the sino-atrial node and the atrioventricular node) in mice (52). Homozygous TR $\alpha 1^{-l-}$ mice present an average heart rate that is $20 \%$ lower than that of control animals, and prolonged QRS and QTend duration, suggesting that TR $\alpha 1$ tightly controls cardiac pacemaking and ventricular repolarization (20). Moreover, mice hetero- zygous for a mutant $\mathrm{TR} \alpha 1^{+/ \mathrm{m}}$ exhibit bradycardia, reduced contractility, and delayed relaxation time of isolated cardiomyocytes (53).

Most of the injected embryos presented vascular defects, including a reduction of the CV plexus, frequently in combination with misguided branches and premature ending of the intersomitic vessels at $2 \mathrm{dpf}$. At $3 \mathrm{dpf}$, the embryos also exhibited a reduced or absent development of the subintestinal vessels, a complex network of vessels that delivers blood to the developing digestive tract and which is a good indicator of angiogenesis processes $(39,54)$. The proangiogenic effect of TH has been studied in rats, which displayed substantial coronary angiogenesis concomitant with the upregulation of the basic fibroblast growth factor (Fgf2) upon $\mathrm{T} 4$ treatment (55). Furthermore, it has been reported that $\mathrm{TH}$ have a relevant impact on brain vasculature development (56). Hypothyroid rats have decreased brain angiogenesis with a reduced complexity and density of microvessels, in parallel with a reduced expression of Fgf2 and vascular endothelial growth factor $\mathrm{A}$; all these functions could be rescued by T3 treatment (56). Interestingly, physiologic concentrations of TH stimulate the proliferation of brain-derived endothelial cells in vitro, accompanied by the downregulation 

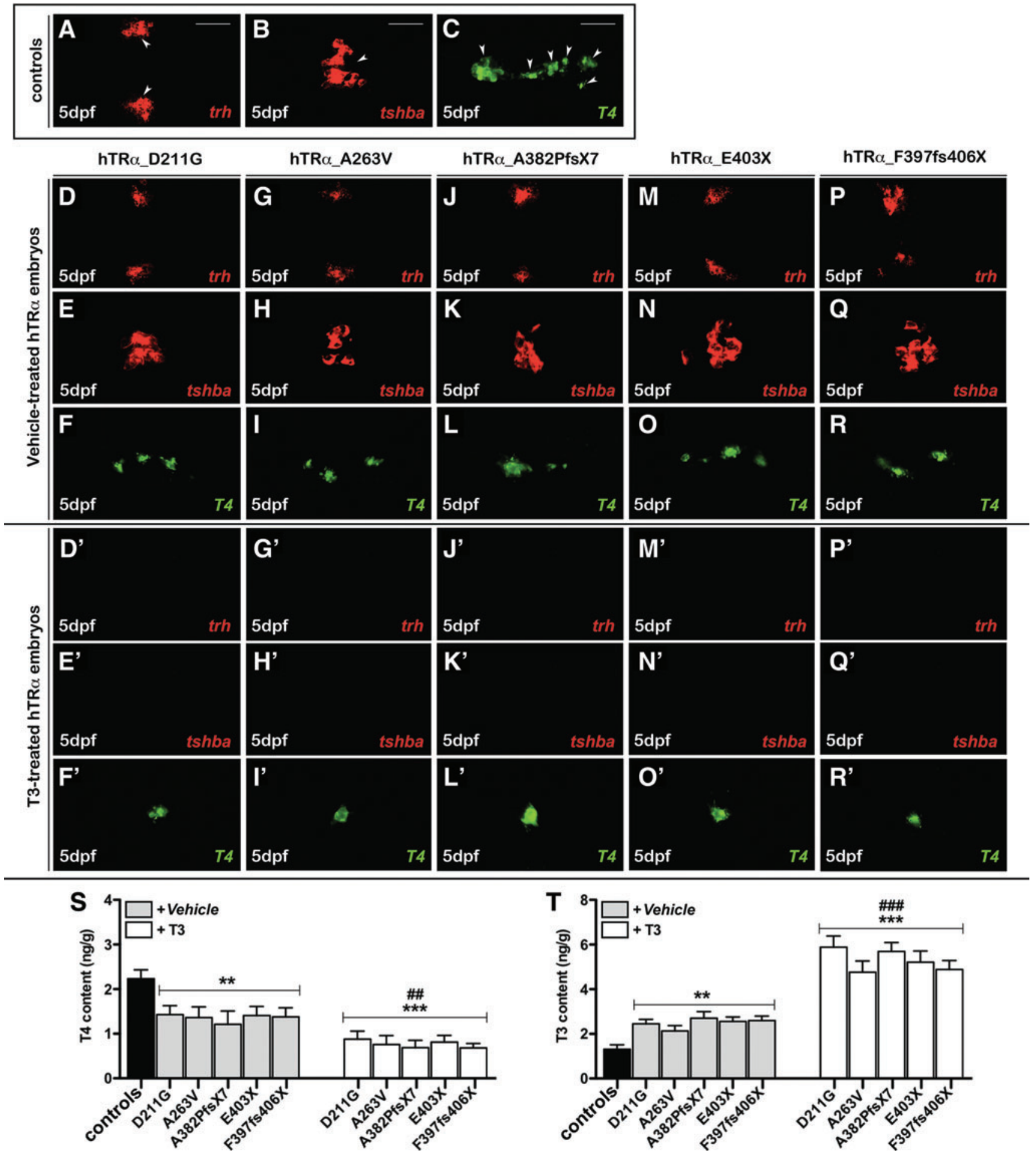

FIG. 7. Evaluation of hypothalamic-pituitary-thryroid (HPT) axis function and thyroid hormone levels of hTR $\alpha$-injected larvae. WISH of trh and tshba, and immunohistochemistry (IHC) of thyroxine-producing follicles followed by confocal microscopy in controls acquired in ventral view, head to the left (A-C; arrowheads). Scale bars in (A-C): $250 \mu \mathrm{m}$ (objective $20 \times)$. (D) and $\left(\mathbf{D}^{\prime}\right),(\mathbf{G})$ and $\left(\mathbf{G}^{\prime}\right),(\mathbf{J})$ and $\left(\mathbf{J}^{\prime}\right),(\mathbf{M})$ and $\left(\mathbf{M}^{\prime}\right)$, and $(\mathbf{P})$ and $\left(\mathbf{P}^{\prime}\right)$ Expression of the hypothalamic trh in embryos injected with the various hTR $\alpha$ transcripts followed by treatment with vehicle or T3. $(\mathbf{E})$ and $\left(\mathbf{E}^{\prime}\right),(\mathbf{H})$ and $\left(\mathbf{H}^{\prime}\right)$, $(\mathbf{K})$ and $\left(\mathbf{K}^{\prime}\right),(\mathbf{N})$ and $\left(\mathbf{N}^{\prime}\right)$, and $(\mathbf{Q})$ and $\left(\mathbf{Q}^{\prime}\right)$ Expression of the pituitary tshba in vehicle- or T3-treated hTR $\alpha$-injected embryos. $(\mathbf{F})$ and $\left(\mathbf{F}^{\prime}\right),(\mathbf{I})$ and $\left(\mathbf{I}^{\prime}\right),(\mathbf{L})$ and $\left(\mathbf{L}^{\prime}\right),(\mathbf{O})$ and $\left(\mathbf{O}^{\prime}\right)$, and $(\mathbf{R})$ and $\left(\mathbf{R}^{\prime}\right)$ T4-producing follicles in vehicle- or T3treated hTR $\alpha$-injected embryos. (S) and (T) Quantification with specific enzymatic links immunosorbent assays of the total T4 and T3 content (ng/g fish weight) of uninjected and injected larvae at $5 \mathrm{dpf}$ (100 larvae each). **p<0.01 and $* * * p<0.001$ versus controls; \#\#\#p<0.001 versus vehicle-treated hTR $\alpha$ embryos. Color images available online at www.liebertpub.com/thy 
of the apoptosis-related genes Bcl2 and Bad (56). Therefore, the present results confirm a central role for TH in angiogenesis and strongly indicate that these angiogenic effects are mediated by TR $\alpha$.

The injection of hTR $\alpha$ mutants in zebrafish embryos produced marked blood stasis at the level of the CV plexus and a low amount of circulating erythrocytes at $2 \mathrm{dpf}$. Analysis of the hemoglobin content by $o$-dianisidine staining up to $5 \mathrm{dpf}$ confirmed that anemia was evident in $>90 \%$ of embryos exhibiting a dramatic reduction of circulating erythrocytes. Anemia in RTH $\alpha$ patients correlates with documented abnormal erythropoiesis and a reduced hematocrit in $\mathrm{TR} \alpha^{-1-}$ or TR $\alpha \mathrm{PV} /+$ mutant mice $(57,58)$, although the mechanisms of defective proliferation or differentiation of erythroid progenitors remain to be elucidated. In vitro and in vivo studies demonstrated that the T3-dependent TR $\alpha$ induction can affect the signal transduction pathways implicated in proliferation of hematopoietic progenitors for the erythroid lineage (59-62).

It was also observed that the expression of the hTR $\alpha$ variants affects motorneuron development, resulting in reduced spontaneous movements of embryos at $1 \mathrm{dpf}$ and in an almost complete swimming inability of the developing larvae at 3 and $5 \mathrm{dpf}$. Most of the hTR $\alpha$-injected embryos presented with moderate to severe alterations of primary and secondary motorneurons, but in the presence of normal development of the muscle fibers, suggesting that $h \mathrm{TR} \alpha$ is implicated in the establishment of muscle innervation. Consistently, RTH $\alpha$ patients present a reduced muscle tone with normal power but with impairment in gross and fine motor coordination, resulting in slow and clumsy movements (11). Moreover, neonatal hypothyroidism induced in rats by propylthiouracil treatment during gestation was associated with a reduced innervation of the muscle fibers and delayed movements, whereas these processes were accelerated in hyperthyroid conditions (63). Interestingly, locomotor dysfunctions have also been described in TR $\alpha 1-\mathrm{R} 384 \mathrm{C}$ mice, which suffer from reduced grip strength, poor limb coordination, and an abnormal gait, findings that correlate with an aberrant development of GABAergic interneurons (64).

Finally, the profound alterations in cartilage and bone development could represent the zebrafish correlate of the delayed bone development and skeletal dysplasia described in RTH $\alpha$ patients (11) and in genetically modified mice (1618). The skeleton is a target tissue that is highly sensitive to $\mathrm{TH}$, and $\mathrm{T} 3$ exerts anabolic actions during growth and catabolic effects in adult bone (65). Both hyperthyroid and hypothyroid conditions are associated with secondary osteoporosis and osteoarthritis or delayed bone maturation and skeletal dysplasia, respectively (65). Moreover, the similar skeletal phenotypes of $\mathrm{TR} \alpha^{-1-}$ and $\mathrm{TR} \alpha^{-1-} \mathrm{TR} \beta^{\beta^{-1-}}$ mice suggested that $\operatorname{TR} \beta$ is not essential for the normal postnatal maturation of bone, and that $\operatorname{TR} \beta$ cannot substitute for $\operatorname{TR} \alpha$ in this process (66). The present results thus further confirm the relevant role exerted by $\mathrm{TR} \alpha$ during bone development in vertebrates.

\section{Conclusions}

In conclusion, the injection of human THRA mutant transcripts in zebrafish (one- to two-cell stage) embryos can cause tissue-specific interference in $\mathrm{TH}$ action that recapitulates the biochemical and clinical features of RTH $\alpha$ patients. This study reveals for the first time the involvement of TR $\alpha$ in the angiogenic processes.

Since high doses of T3 can overcome the binding defect and negative action of human $\mathrm{TR} \alpha$ mutants, this "tailormade" zebrafish model can be useful to shed light on the molecular mechanisms and functional consequences of the newly discovered human THRA variants, and to test new compounds that may be designed to overcome the specific deleterious effects of $\mathrm{TR} \alpha$ mutations, perhaps avoiding the thyrotoxic effects on TR $\beta$-expressing tissues.

\section{Acknowledgments}

The authors wish to thank Prof. Krishna Chatterjee and Dr. Maura Agostini (Cambridge, United Kingdom), and Prof. Robin Peeters (Rotterdam, NL) for the supply of the mutant hTR $\alpha$ plasmids.

This research was supported by funding from the Italian Ministry of Health, Rome, Italy (grant RF-2010-2309484), and the Ricerca Corrente of IRCCS Istituto Auxologico Italiano, Milan, Italy (Zebratir grant: 05C102_2011).

\section{Author Disclosure Statement}

The authors have nothing to disclose.

\section{References}

1. Bochukova E, Schoenmakers N, Agostini M, Schoenmakers E, Rajanayagam O, Keogh JM, Henning E, Reinemund J, Gevers E, Sarri M, Downes K, Offiah A, Albanese A, Halsall D, Schwabe JW, Bain M, Lindley K, Muntoni F, Vargha-Khadem F, Dattani M, Farooqi IS, Gurnell M, Chatterjee K 2012 A mutation in the thyroid hormone receptor alpha gene. N Engl J Med 366:243-249.

2. van Mullem A, van Heerebeek R, Chrysis D, Visser E, Medici M, Andrikoula M, Tsatsoulis A, Peeters R, Visser TJ 2012 Clinical phenotype and mutant TRalpha1. N Engl J Med 366: 1451-1453.

3. Moran C, Schoenmakers N, Agostini M, Schoenmakers E, Offiah A, Kydd A, Kahaly G, Mohr-Kahaly S, Rajanayagam O, Lyons G, Wareham N, Halsall D, Dattani M, Hughes S, Gurnell M, Park SM, Chatterjee K 2013 An adult female with resistance to thyroid hormone mediated by defective thyroid hormone receptor alpha. J Clin Endocrinol Metab 98:4254-4261.

4. van Mullem AA, Chrysis D, Eythimiadou A, Chroni E, Tsatsoulis A, de Rijke YB, Visser WE, Visser TJ, Peeters RP 2013 Clinical phenotype of a new type of thyroid hormone resistance caused by a mutation of the TRalpha1 receptor: consequences of LT4 treatment. J Clin Endocrinol Metab 98:3029-3038.

5. Moran C, Agostini M, Visser WE, Schoenmakers E, Schoenmakers N, Offiah AC, Poole K, Rajanayagam O, Lyons G, Halsall D, Gurnell M, Chrysis D, Efthymiadou A, Buchanan C, Aylwin S, Chatterjee KK 2014 Resistance to thyroid hormone caused by a mutation in thyroid hormone receptor (TR)alpha1 and TRalpha2: clinical, biochemical, and genetic analyses of three related patients. Lancet Diabetes Endocrinol 2:619-626.

6. van Mullem AA, Visser TJ, Peeters RP 2014 Clinical consequences of mutations in thyroid hormone receptoralpha1. Eur Thyroid J 3:17-24.

7. Espiard S, Savagner F, Flamant F, Vlaeminck-Guillem V, Guyot R, Munier M, d'Herbomez M, Bourguet W, Pinto G, 
Rose C, Rodien P, Wemeau JL 2015 A novel mutation in THRA gene associated with an atypical phenotype of resistance to thyroid hormone. J Clin Endocrinol Metab 100:2841-2848.

8. Yuen RK, Thiruvahindrapuram B, Merico D, Walker S, Tammimies K, Hoang N, Chrysler C, Nalpathamkalam T, Pellecchia G, Liu Y, Gazzellone MJ, D'Abate L, Deneault E, Howe JL, Liu RS, Thompson A, Zarrei M, Uddin M, Marshall CR, Ring RH, Zwaigenbaum L, Ray PN, Weksberg R, Carter MT, Fernandez BA, Roberts W, Szatmari P, Scherer SW 2015 Whole-genome sequencing of quartet families with autism spectrum disorder. Nat Med 21:185-191.

9. Tylki-Szymanska A, Acuna-Hidalgo R, Krajewska-Walasek M, Lecka-Ambroziak A, Steehouwer M, Gilissen C, Brunner HG, Jurecka A, Rozdzynska-Swiatkowska A, Hoischen A, Chrzanowska KH 2015 Thyroid hormone resistance syndrome due to mutations in the thyroid hormone receptor alpha gene (THRA). J Med Genet 52:312-316.

10. van Gucht AL, Meima ME, Zwaveling-Soonawala N, Visser WE, Fliers E, Wennink JM, Henny C, Visser TJ, Peeters RP, van Trotsenburg AS 2016 Resistance to thyroid hormone alpha in an 18-month-old girl: clinical, therapeutic, and molecular characteristics. Thyroid 26:338-346.

11. Moran C, Chatterjee K 2015 Resistance to thyroid hormone due to defective thyroid receptor alpha. Best Pract Res Clin Endocrinol Metab 29:647-657.

12. Cheng SY 2005 Isoform-dependent actions of thyroid hormone nuclear receptors: lessons from knockin mutant mice. Steroids 70:450-454.

13. Flamant F, Quignodon L 2010 Use of a new model of transgenic mice to clarify the respective functions of thyroid hormone receptors in vivo. Heart Failure Rev 15:117120.

14. Kaneshige M, Suzuki H, Kaneshige K, Cheng J, Wimbrow $\mathrm{H}$, Barlow C, Willingham MC, Cheng S 2001 A targeted dominant negative mutation of the thyroid hormone alpha 1 receptor causes increased mortality, infertility, and dwarfism in mice. Proc Natl Acad Sci U S A 98:15095-15100.

15. Liu YY, Schultz JJ, Brent GA 2003 A thyroid hormone receptor alpha gene mutation $(\mathrm{P} 398 \mathrm{H})$ is associated with visceral adiposity and impaired catecholamine-stimulated lipolysis in mice. J Biol Chem 278:38913-38920.

16. O'Shea PJ, Bassett JH, Sriskantharajah S, Ying H, Cheng SY, Williams GR 2005 Contrasting skeletal phenotypes in mice with an identical mutation targeted to thyroid hormone receptor alpha1 or beta. Mol Endocrinol 19:30453059.

17. O'Shea PJ, Williams GR 2002 Insight into the physiological actions of thyroid hormone receptors from genetically modified mice. J Endocrinol 175:553-570.

18. Tinnikov A, Nordstrom K, Thoren P, Kindblom JM, Malin S, Rozell B, Adams M, Rajanayagam O, Pettersson S, Ohlsson C, Chatterjee K, Vennstrom B 2002 Retardation of post-natal development caused by a negatively acting thyroid hormone receptor alpha1. EMBO J 21:5079-5087.

19. Vennstrom B, Mittag J, Wallis K 2008 Severe psychomotor and metabolic damages caused by a mutant thyroid hormone receptor alpha 1 in mice: can patients with a similar mutation be found and treated? Acta Paediatr 97:16051610.

20. Wikstrom L, Johansson C, Salto C, Barlow C, Campos Barros A, Baas F, Forrest D, Thoren P, Vennstrom B 1998 Abnormal heart rate and body temperature in mice lacking thyroid hormone receptor alpha 1. EMBO J 17:455-461.
21. Marelli F, Carra S, Agostini M, Cotelli F, Peeters R, Chatterjee K, Persani L 2016 Patterns of thyroid hormone receptor expression in zebrafish and generation of a novel model of resistance to thyroid hormone action. Mol Cell Endocrinol 424:102-117.

22. Santoro MM, Samuel T, Mitchell T, Reed JC, Stainier DY 2007 Birc2 (cIap1) regulates endothelial cell integrity and blood vessel homeostasis. Nature Genet 39:1397-1402.

23. Fishman MC, Stainier DY, Breitbart RE, Westerfield M 1997 Zebrafish: genetic and embryological methods in a transparent vertebrate embryo. Methods Cell Biol 52:67-82.

24. Kimmel CB, Ballard WW, Kimmel SR, Ullmann B, Schilling TF 1995 Stages of embryonic development of the zebrafish. Dev Dynam 203:253-310.

25. Thisse B, Thisse C 2005 Functions and regulations of fibroblast growth factor signaling during embryonic development. Dev Biol 287:390-402.

26. Yelon D, Horne SA, Stainier DY 1999 Restricted expression of cardiac myosin genes reveals regulated aspects of heart tube assembly in zebrafish. Dev Biol 214:23-37.

27. Porazzi P, Marelli F, Benato F, de Filippis T, Calebiro D, Argenton F, Tiso N, Persani L 2012 Disruptions of global and JAGGED1-mediated notch signaling affect thyroid morphogenesis in the zebrafish. Endocrinology 153:56455658.

28. Opitz R, Maquet E, Zoenen M, Dadhich R, Costagliola S 2011 TSH receptor function is required for normal thyroid differentiation in zebrafish. Mol Endocrinol 25:1579-1599.

29. Walpita CN, Crawford AD, Janssens ED, Van der Geyten S, Darras VM 2009 Type 2 iodothyronine deiodinase is essential for thyroid hormone-dependent embryonic development and pigmentation in zebrafish. Endocrinology 150:530-539.

30. Guo C, Chen X, Song H, Maynard MA, Zhou Y, Lobanov AV, Gladyshev VN, Ganis JJ, Wiley D, Jugo RH, Lee NY, Castroneves LA, Zon LI, Scanlan TS, Feldman HA, Huang SA 2014 Intrinsic expression of a multiexon type 3 deiodinase gene controls zebrafish embryo size. Endocrinology 155:4069-4080.

31. Menelaou E, Husbands EE, Pollet RG, Coutts CA, Ali DW, Svoboda KR 2008 Embryonic motor activity and implications for regulating motoneuron axonal pathfinding in zebrafish. Eur J Neurosci 28:1080-1096.

32. Schwerte T, Uberbacher D, Pelster B 2003 Non-invasive imaging of blood cell concentration and blood distribution in zebrafish Danio rerio incubated in hypoxic conditions in vivo. J Exp Biol 206:1299-1307.

33. Childs S, Chen JN, Garrity DM, Fishman MC 2002 Patterning of angiogenesis in the zebrafish embryo. Development 129:973-982.

34. Detrich HW 3rd, Kieran MW, Chan FY, Barone LM, Yee K, Rundstadler JA, Pratt S, Ransom D, Zon LI 1995 Intraembryonic hematopoietic cell migration during vertebrate development. Proc Natl Acad Sci U S A 92:1071310717.

35. Walker MB, Kimmel CB 2007 A two-color acid-free cartilage and bone stain for zebrafish larvae. Biotech Histochem 82:23-28.

36. Yu L, Deng J, Shi X, Liu C, Yu K, Zhou B 2010 Exposure to DE-71 alters thyroid hormone levels and gene transcription in the hypothalamic-pituitary-thyroid axis of zebrafish larvae. Aquatic Toxicol 97:226-233.

37. Wang Q, Liang K, Liu J, Yang L, Guo Y, Liu C, Zhou B 2013 Exposure of zebrafish embryos/larvae to TDCPP 
alters concentrations of thyroid hormones and transcriptions of genes involved in the hypothalamic-pituitarythyroid axis. Aquatic Toxicol 126:207-213.

38. Isogai S, Horiguchi M, Weinstein BM 2001 The vascular anatomy of the developing zebrafish: an atlas of embryonic and early larval development. Dev Biol 230:278-301.

39. Lenard A, Daetwyler S, Betz C, Ellertsdottir E, Belting HG, Huisken J, Affolter M 2015 Endothelial cell self-fusion during vascular pruning. PLoS Biol 13:e1002126.

40. Ransom DG, Haffter P, Odenthal J, Brownlie A, Vogelsang E, Kelsh RN, Brand M, van Eeden FJ, Furutani-Seiki M, Granato M, Hammerschmidt M, Heisenberg CP, Jiang YJ, Kane DA, Mullins MC, Nusslein-Volhard C 1996 Characterization of zebrafish mutants with defects in embryonic hematopoiesis. Development 123:311-319.

41. Eisen JS 1991 Motoneuronal development in the embryonic zebrafish. Science 242:569-572.

42. Myers PZ, Eisen JS, Westerfield M 1986 Development and axonal outgrowth of identified motoneurons in the zebrafish. J Neurosci 6:2278-2289.

43. Porazzi P, Calebiro D, Benato F, Tiso N, Persani L 2009 Thyroid gland development and function in the zebrafish model. Mol Cell Endocrinol 312:14-23.

44. Nakano K, Matsushita A, Sasaki S, Misawa H, Nishiyama K, Kashiwabara Y, Nakamura H 2004 Thyroid-hormonedependent negative regulation of thyrotropin beta gene by thyroid hormone receptors: study with a new experimental system using CV1 cells. Biochem J 378:549-557.

45. Bragato C, Gaudenzi G, Blasevich F, Pavesi G, Maggi L, Giunta M, Cotelli F, Mora M 2016 Zebrafish as a model to investigate dynamin 2-related diseases. Sci Rep 6:20466.

46. Barca-Mayo O, Liao XH, Alonso M, Di Cosmo C, Hernandez A, Refetoff S, Weiss RE 2011 Thyroid hormone receptor alpha and regulation of type 3 deiodinase. Mol Endocrinol 25:575-583.

47. Flamant F, Samarut J 2003 Thyroid hormone receptors: lessons from knockout and knock-in mutant mice. Trends Endocrinol Metab 14:85-90.

48. Stainier DY 2001 Zebrafish genetics and vertebrate heart formation. Nat Rev Genet 2:39-48.

49. Stainier DY, Fishman MC 1992 Patterning the zebrafish heart tube: acquisition of anteroposterior polarity. Dev Biol 153:91-101.

50. Stainier DY, Lee RK, Fishman MC 1993 Cardiovascular development in the zebrafish. I. Myocardial fate map and heart tube formation. Development 119:31-40.

51. Staudt D, Stainier D 2012 Uncovering the molecular and cellular mechanisms of heart development using the zebrafish. Ann Rev Genet 46:397-418.

52. Stoykov I, Zandieh-Doulabi B, Moorman AF, Christoffels V, Wiersinga WM, Bakker O 2006 Expression pattern and ontogenesis of thyroid hormone receptor isoforms in the mouse heart. J Endocrinol 189:231-245.

53. Mittag J, Davis B, Vujovic M, Arner A, Vennstrom B 2010 Adaptations of the autonomous nervous system controlling heart rate are impaired by a mutant thyroid hormone receptor-alpha1. Endocrinology 151:2388-2395.

54. Serbedzija GN, Flynn E, Willett CE 1999 Zebrafish angiogenesis: a new model for drug screening. Angiogenesis 3:353-359.
55. Tomanek RJ, Doty MK, Sandra A 1998 Early coronary angiogenesis in response to thyroxine: growth characteristics and upregulation of basic fibroblast growth factor. Circ Res 82:587-593.

56. Zhang L, Cooper-Kuhn CM, Nannmark U, Blomgren K, Kuhn HG 2010 Stimulatory effects of thyroid hormone on brain angiogenesis in vivo and in vitro. J Cer Blood Flow Metab 30:323-335.

57. Itoh Y, Esaki T, Kaneshige M, Suzuki H, Cook M, Sokoloff L, Cheng SY, Nunez J 2001 Brain glucose utilization in mice with a targeted mutation in the thyroid hormone alpha or beta receptor gene. Proc Natl Acad Sci U S A 98:99139918.

58. Kendrick TS, Payne CJ, Epis MR, Schneider JR, Leedman PJ, Klinken SP, Ingley E 2008 Erythroid defects in TRalpha-/- mice. Blood 111:3245-3248.

59. Golde DW, Bersch N, Chopra IJ, Cline MJ 1977 Thyroid hormones stimulate erythropoiesis in vitro. Br J Haematol 37:173-177.

60. Malgor LA, Valsecia ME, Verges EG, de Markowsky EE 1995 Enhancement of erythroid colony growth by triiodothyronine in cell cultures from bone marrow of normal and anemic rats with chronic renal failure. Acta Phys Pharmacol Ther 45:79-86.

61. Perrin MC, Blanchet JP, Mouchiroud G 1997 Modulation of human and mouse erythropoiesis by thyroid hormone and retinoic acid: evidence for specific effects at different steps of the erythroid pathway. Hematol Cell Ther 39:1926.

62. Sullivan PS, McDonald TP 1992 Thyroxine suppresses thrombocytopoiesis and stimulates erythropoiesis in mice. Proc Soc Exp Biol Med 201:271-277.

63. Kawa K, Obata K 1982 Altered developmental changes of neuromuscular junction in hypo- and hyperthyroid rats. J Physiol 329:143-161.

64. Wallis K, Sjogren M, van Hogerlinden M, Silberberg G, Fisahn A, Nordstrom K, Larsson L, Westerblad H, Morreale de Escobar G, Shupliakov O, Vennstrom B 2008 Locomotor deficiencies and aberrant development of subtypespecific GABAergic interneurons caused by an unliganded thyroid hormone receptor alpha1. J Neurosci 28:19041915.

65. Bassett JH, Williams GR 2016 Role of thyroid hormones in skeletal development and bone maintenance. Endocr Rev 37:135-187.

66. Gauthier K, Chassande O, Plateroti M, Roux JP, Legrand C, Pain B, Rousset B, Weiss R, Trouillas J, Samarut J 1999 Different functions for the thyroid hormone receptors TRalpha and TRbeta in the control of thyroid hormone production and post-natal development. EMBO J 18:623-631.

Address correspondence to: Luca Persani, $M D$

Division of Endocrine and Metabolic Diseases Istituto Auxologico Italiano Piazzale Brescia 20 20149 Milan

Italy

E-mail: luca.persani@unimi.it 


\section{Supplementary Data}

\section{Supplementary References}

1. van Gucht AL, Meima ME, Zwaveling-Soonawala N, Visser WE, Fliers E, Wennink JM, Henny C, Visser TJ, Peeters RP, van Trotsenburg AS 2016 Resistance to thyroid hormone alpha in an 18-month-old girl: clinical, therapeutic, and molecular characteristics. Thyroid 26:338-346.

2. Moran C, Agostini M, Visser WE, Schoenmakers E, Schoenmakers N, Offiah AC, Poole K, Rajanayagam O, Lyons G, Halsall D, Gurnell M, Chrysis D, Efthymiadou A, Buchanan C, Aylwin S, Chatterjee KK 2014 Resistance to thyroid hormone caused by a mutation in thyroid hormone receptor (TR)alpha1 and TRalpha2: clinical, biochemical, and genetic analyses of three related patients. Lancet Diabetes Endocrinol 2:619-626.

3. Moran C, Schoenmakers N, Agostini M, Schoenmakers E, Offiah A, Kydd A, Kahaly G, Mohr-Kahaly S, Rajanayagam O, Lyons G, Wareham N, Halsall D, Dattani M, Hughes S, Gurnell M, Park SM, Chatterjee K 2013 An adult female with resistance to thyroid hormone mediated by defective thyroid hormone receptor alpha. J Clin Endocrinol Metab 98:4254-4261.

4. van Mullem A, van Heerebeek R, Chrysis D, Visser E, Medici M, Andrikoula M, Tsatsoulis A, Peeters R, Visser TJ 2012 Clinical phenotype and mutant TRalpha1. New Engl J Med 366:1451-1453.

5. Bochukova E, Schoenmakers N, Agostini M, Schoenmakers E, Rajanayagam O, Keogh JM, Henning E, Reinemund J, Gevers E, Sarri M, Downes K, Offiah A, Albanese A, Halsall D, Schwabe JW, Bain M, Lindley K, Muntoni F, Vargha-Khadem F, Dattani M, Farooqi IS, Gurnell M, Chatterjee K 2012 A mutation in the thyroid hormone receptor alpha gene. New Engl J Med 366:243249.

6. Marelli F, Carra S, Agostini M, Cotelli F, Peeters R, Chatterjee K, Persani L 2016 Patterns of thyroid hormone receptor expression in zebrafish and generation of a novel model of resistance to thyroid hormone action. Mol Cell Endocrinol 424:102-117.

SUPPLEMENTARY FIG. S1. Alignment of the protein sequences of human and zebrafish TRs. Alignment of the protein sequences of the human (hTR) and zebrafish (zTR) receptors: hTR $\alpha 1$ (ref. no. P10827-2) and hTR $\alpha 2$ (ref. no. P10827-1) differ in 80 aminoacids (371-490; blue bold letters); the zTR $\alpha 1 \mathrm{~S}$ (ref. no. Q98867-2) and zTR $\alpha 1 \mathrm{~L}$ (ref. no.
Q98867-1) differ in 14 aminoacids at the C-terminus (413-427; blue bold letters); the zTR $\beta 1 S$ (ref. no. Q9PVE4-2) and zTR $\beta 1$ L (ref. no. Q9PVE4-1) isoforms differ for the insertion of nine residues (172-180; blue bold letters), and zTR $\beta 2$ (ref. no. S6BPQ3) presents an N-terminal domain that is 93-aminoacids longer than TR $\beta 1$ isoforms. The residues belonging to the transactivation domain (TAD) are reported in gray; those of the DNA binding domain (DBD) are reported in black bold characters with the zinc finger domains in green; those of the hinge region (HR) are in italic, and those of the ligand-binding domain (LBD) are in light blue. The residues affected by the human THRA mutations (D211G (1), A263V (2), A382PfsX7 (3), F397fs406X (4) and E403X (5)) are highlighted in bold. 
THY-2016-0373-ver9-Marelli-Suppl_1P.3d 11/28/16 5:35pm Page 2

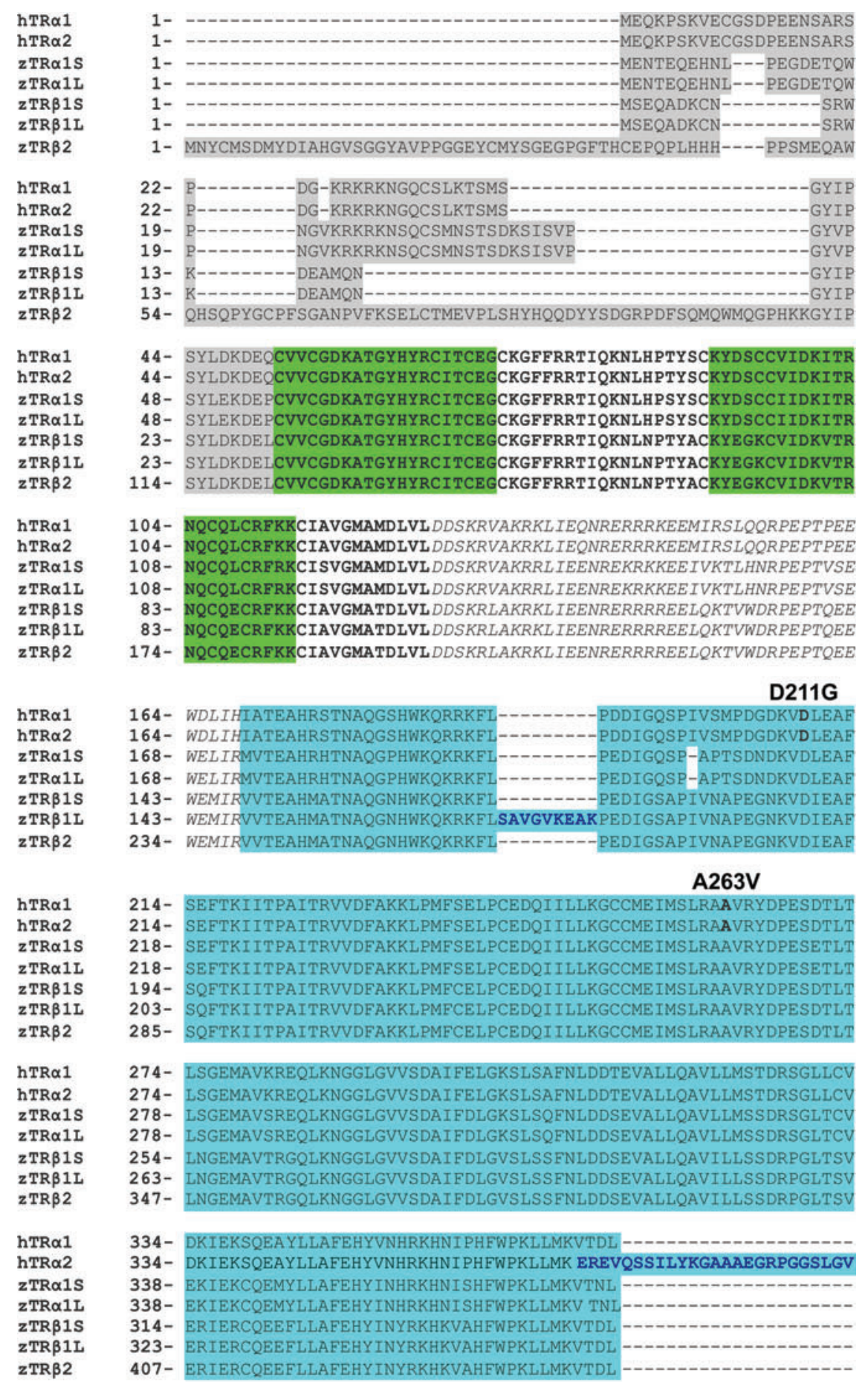

$\mathrm{hTR} \alpha 1$

$\mathrm{hTR} \alpha 2$

zTR $\alpha 15$

$\mathrm{zTR} \alpha 1 \mathrm{~L}$

zTRB1S

zTRB1L

zTRß2

$\mathrm{hTR} \alpha 1$

$\mathrm{hTR} \alpha 2$

zTR $\alpha 1 S$

zTR $\alpha 1 \mathrm{~L}$

zTRB1S

zTRB1L

$z T R \beta 2$

A382PfsX7

373- 394 - HPEGQQLLGMHVVQGPQVRQLEQQLGEAGSLQGPVLQHQSPKSPQQRLLELLHRSGILHA

377- - RMIGACHASRELHM

377- - -

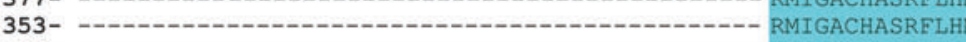

362- -

446- -

386- KVEC----PTELFPPLE----LEVFEDQEV-------------- -410

455- RAVCGEDDSSEADSPSSSEEEPEVCEDLAGNAASP -------- -490

391- KVEC----PTELFPPLF----LEVEEDQEV-------------- -413

391- KVEC----PTELFPPLE----LEVEEDQEGSTGVAAQEDGSCLR -427

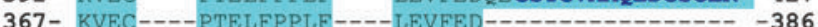

376- KVEC---PTELFPPLF---LEVEED--_-_-_--- - 395

465- KVEC----PTELPPPLF----LEVFED---- 

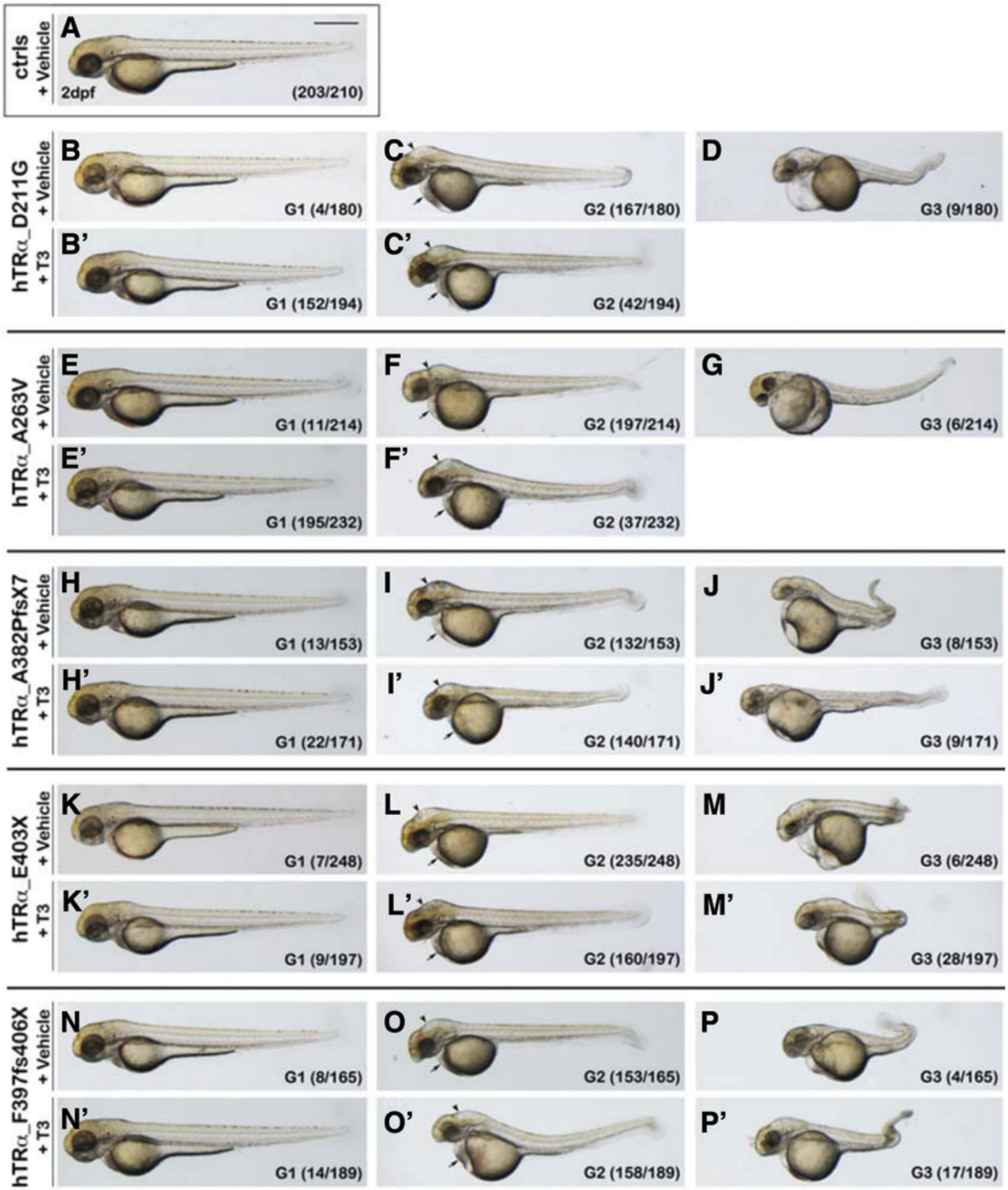

SUPPLEMENTAL FIG. S2. Morphological phenotypes of hTR $\alpha$-injected embryos. Zebrafish embryos at one to two-cell stage were injected with $80 \mathrm{pg} /$ embryo of hTR $\alpha$ mRNAs and treated with DMSO (vehicle) or $20 \mu \mathrm{M}$ of T3, and were both compared with vehicle-treated controls (A); scale bar: $50 \mu \mathrm{m}$. At $2 \mathrm{dpf}$, hTR $\alpha$-injected embryos displayed variable phenotypes. $(\mathbf{B})$ and $\left(\mathbf{B}^{\prime}\right),(\mathbf{E})$ and $\left(\mathbf{E}^{\prime}\right),(\mathbf{H})$ and $\left(\mathbf{H}^{\prime}\right),(\mathbf{K})$ and $\left(\mathbf{K}^{\prime}\right)$, and $(\mathbf{N})$ and $\left(\mathbf{N}^{\prime}\right)$ Group 1 (G1) including unaffected embryos (comparable to controls). $(\mathbf{C})$ and $\left(\mathbf{C}^{\prime}\right),(\mathbf{F})$ and $\left(\mathbf{F}^{\prime}\right),(\mathbf{I})$ and $\left(\mathbf{I}^{\prime}\right),(\mathbf{L})$ and $\left(\mathbf{L}^{\prime}\right)$, and $(\mathbf{O})$ and $\left(\mathbf{O}^{\prime}\right) \mathrm{G} 2$ including embryos with moderate defects such as small head, reduced body length, and brain (arrow head) or cardiac (arrow) edema. (D) and $\left(\mathbf{D}^{\prime}\right)$, $(\mathbf{G})$ and $\left(\mathbf{G}^{\prime}\right),(\mathbf{J})$ and $\left(\mathbf{J}^{\prime}\right),(\mathbf{M})$ and $\left(\mathbf{M}^{\prime}\right)$, and $(\mathbf{P})$ and $\left(\mathbf{P}^{\prime}\right)$ G3 including embryos with severe defects of development that lead to death within $4 \mathrm{dpf}$. The number of $\mathrm{hTR} \alpha$-injected embryos classified within these three major groups is reported in parentheses. 

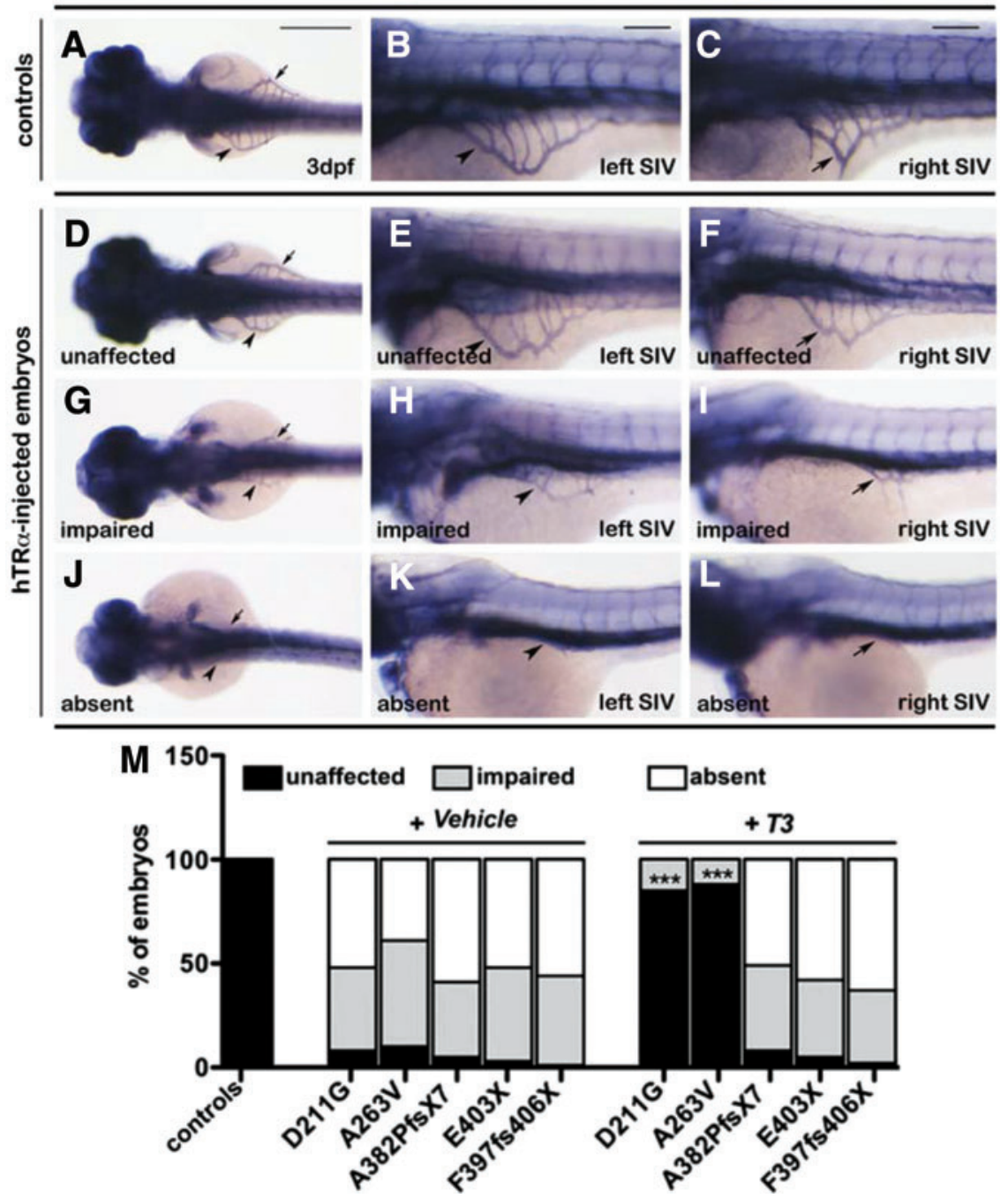

SUPPLEMENTARY FIG. S3. Development of subintestinal vessels (SIV) in hTR $\alpha$-injected embryos. (A-C) Representation of left (arrowheads) and right (arrows) SIV of control fish at $3 \mathrm{dpf}$ in dorsal (A) and lateral views (B and C). Scale bars in (A): $50 \mu \mathrm{m}$; and $(\mathbf{B})$ and $(\mathbf{C}): 100 \mu \mathrm{m}$. Fish were stained with the endogenous alkaline phosphatase (AP) activity to show the SIV plexus structure. The hTR $\alpha$-injected embryos presented an unaffected SIV ( $8 \% \%$ in $(\mathbf{M}))(\mathbf{D}-\mathbf{F})$ or impaired development of both left and right SIV $(\mathbf{G}-\mathbf{I})$ in $40-50 \%$, or complete SIV absence in $40-60 \%$ of the embryos $(\mathbf{J}-\mathbf{L})$. The rescue rate of the unaffected phenotype by T3 treatment in embryos injected with hTR $\alpha$ variants is reported in (M). $* * * p<0.001$ versus vehicle embryos. All images are representative of three independent experiments (20 embryos each). 

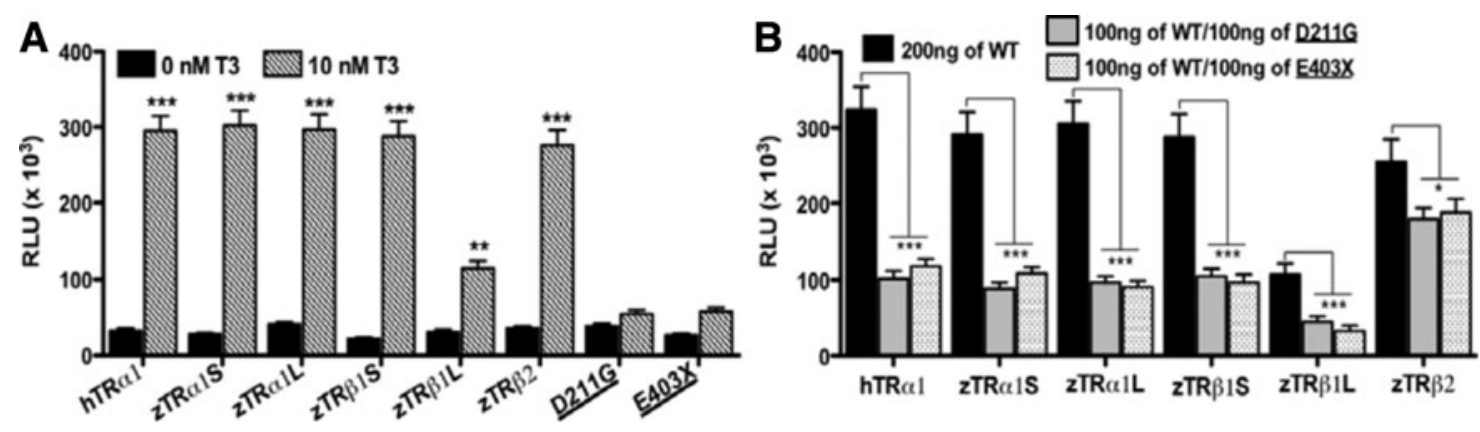

SUPPLEMENTARY FIG. S4. In vitro analysis of the activity of hTR $\alpha$ variants on the zebrafish receptors. (A) The T3dependent luciferase activation is reported. COS7 cells were transfected with $200 \mathrm{ng}$ of wild-type hTR $\alpha 1$ or zTRs (zTR $\alpha 1 S$, zTR $\alpha 1 \mathrm{~L}, \mathrm{zTR} \beta 1 \mathrm{~S}$, zTR $\beta 1 \mathrm{~L}$, and zTR $\beta 2$ ) or hTR $\alpha$ mutants (D211G or E403X), together with pAL-tkLUC and $\beta$ galactosidase reporters either in the absence (black bars) or presence of $10 \mathrm{nM}$ of T3 (hatched bars). The transcriptional activity is given in relative luciferase units $\left(\mathrm{RLU} \times 10^{3}\right)$. Each value represents the mean $\pm S D$ of the pAL-luciferase activity/ $\beta$-galactosidase activity ratio of three independent experiments. As previously reported (6), the zTR $\beta 1 \mathrm{~L}$ has a diminished binding affinity for T3. ***p $<0.001$ or $* * p<0.01$ versus black bar. (B) Transcriptional activity in presence of $10 \mathrm{nM}$ of T3 after transfection of COS7 cells with wild-type receptors $(200 \mathrm{ng})$ or co-transfection of equal combinations of wild-type and mutant receptors (D211G or E403X; $100 \mathrm{ng}$ WT $+100 \mathrm{ng}$ MUT). $* * * p<0.001$ or $* p<0.05$ versus wild type. The luciferase activity is calculated as described above. The $\mathrm{hTR} \alpha$ variants appear to exert a significant dominant negative action on the in vitro transcriptional activity of all zTRs, but with a diminished effect on that of zTR $\beta 2$. 

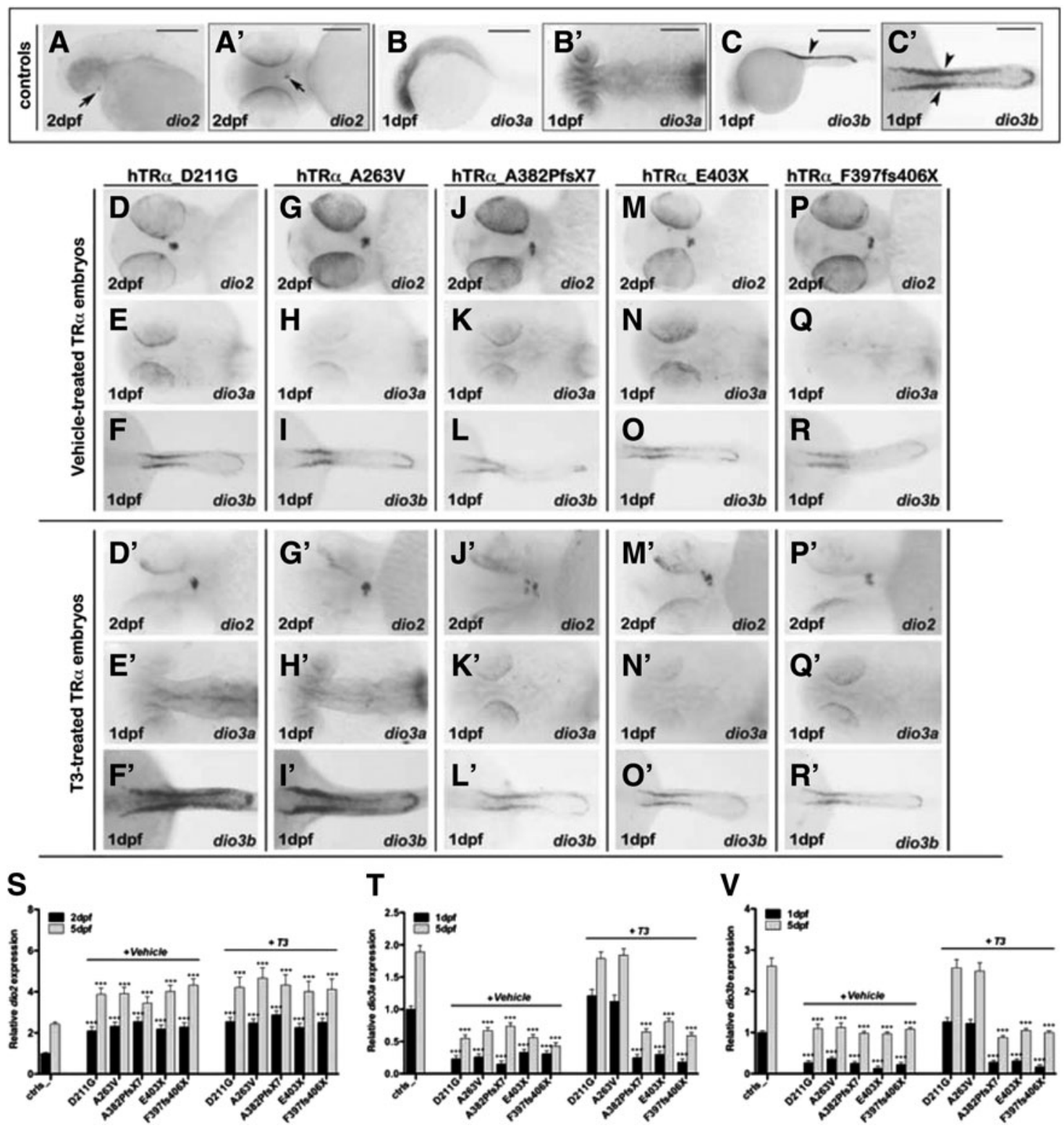

SUPPLEMENTARY FIG. S5. Analysis of zebrafish deiodinases' expression by WISH in embryos injected with hTR $\alpha$ variants. Control fish in lateral (A) and ventral (A') view: WISH of dio2 (arrows) localized in the pituitary at 2 dpf; WISH of $\operatorname{dio} 3 a\left(\mathbf{B}\right.$ and $\left.\mathbf{B}^{\prime}\right)$ and $\operatorname{dio} 3 b\left(\mathbf{C}\right.$ and $\left.\mathbf{C}^{\prime}\right)$ at $1 \mathrm{dpf}$ that are detectable in brain and pronephros (arrowheads), respectively. Scale bars in (A-C): $50 \mu \mathrm{m}$; and $\left(\mathbf{A}^{\prime}-\mathbf{C}^{\prime}\right): 100 \mu \mathrm{m}$. $(\mathbf{D})$ and $\left(\mathbf{D}^{\prime}\right),(\mathbf{G})$ and $\left(\mathbf{G}^{\prime}\right),(\mathbf{J})$ and $\left(\mathbf{J}^{\prime}\right),(\mathbf{M})$ and $\left(\mathbf{M}^{\prime}\right)$, and $(\mathbf{P})$ and $\left(\mathbf{P}^{\prime}\right)$ : WISH of dio2 in embryos injected with the various hTR $\alpha$ transcripts followed by treatment with vehicle or T3. $(\mathbf{E})$ and $\left(\mathbf{E}^{\prime}\right),(\mathbf{H})$ and $\left(\mathbf{H}^{\prime}\right),(\mathbf{K})$ and $\left(\mathbf{K}^{\prime}\right),(\mathbf{N})$ and $\left(\mathbf{N}^{\prime}\right)$, and $(\mathbf{Q})$ and $\left(\mathbf{Q}^{\prime}\right)$ : WISH of dio3a in vehicle- or T3-treated hTR $\alpha$ injected embryos. $(\mathbf{F})$ and $\left(\mathbf{F}^{\prime}\right)$, (I) and $\left(\mathbf{I}^{\prime}\right),(\mathbf{L})$ and $\left(\mathbf{L}^{\prime}\right),(\mathbf{O})$ and $\left(\mathbf{O}^{\prime}\right)$, and $(\mathbf{R})$ and $\left(\mathbf{R}^{\prime}\right)$ : WISH of dio3b in vehicle- or T3-treated hTR $\alpha$ injected embryos. (S), (T), and (V): qRT-PCR of dio 2 at 2 and $5 \mathrm{dpf}$ and dio3a and dio $3 b$ at 1 and 5 dpf. $* * * p<0.001$ versus controls (ctrls). The whole of these data show a significant increase of dio2 transcripts and a dramatic fall of dio3a/dio $3 b$ transcripts in fish injected with hTR $\alpha$ variants. T3 treatment can rescue dio3a/dio3b expression only in fish injected with the missense variants. 


\section{AUTHOR QUERY FOR THY-2016-0373-VER9-MARELLI_1P}

AU1: Please check that author names appear corrogtly.

AU2: Please check that affiliations are correct. $\Omega$

AU3: Please convert centr tion and/or agitation to gravitational force (expressed in $g$ ), or specify the manufacturer and model of the device 2

AU4: Please check that postal address is correct and complete. 